\title{
Characterization of the Lytic Capability of a LysK-Like Endolysin, Lys-phiSA012, Derived from a Polyvalent Staphylococcus aureus Bacteriophage
}

\author{
Jumpei Fujiki ${ }^{1,+} \mathbb{C}^{\mathbb{D}}$, Tomohiro Nakamura ${ }^{1,+}$, Takaaki Furusawa ${ }^{1}$, Hazuki Ohno ${ }^{1}$, \\ Hiromichi Takahashi ${ }^{1}$, Junya Kitana ${ }^{1}$, Masaru Usui ${ }^{2}$, Hidetoshi Higuchi ${ }^{3}$, Yasunori Tanji ${ }^{4}$ (D), \\ Yutaka Tamura ${ }^{2,5}$ and Hidetomo Iwano ${ }^{1, *}$ (iD) \\ 1 Laboratory of Biochemistry, School of Veterinary Medicine, Rakuno Gakuen University, Ebetsu 069-8501, \\ Japan; j-fujiki@rakuno.ac.jp (J.F.); tomohiro-tobi-@hotmail.co.jp (T.N.); s21441012@stu.rakuno.ac.jp (T.F.); \\ leafmoon-0812@honey.ocn.ne.jp (H.O.); 13ump_fnch@yahoo.co.jp (H.T.); s21361043@stu.rakuno.ac.jp (J.K.) \\ 2 Laboratory of Food Microbiology and Food Safety, School of Veterinary Medicine, Rakuno Gakuen \\ University, Ebetsu 069-8501, Japan; usuima@rakuno.ac.jp (M.U.); tamuray@rakuno.ac.jp (Y.T.) \\ 3 Laboratory of Veterinary Hygiene, School of Veterinary Medicine, Rakuno Gakuen University, \\ Ebetsu 069-8501, Japan; higuchi@rakuno.ac.jp \\ 4 Department of Bioengineering, Tokyo Institute of Technology, Yokohama 226-8502, Japan; \\ ytanji@bio.titech.ac.jp \\ 5 Center for Veterinary Drug Development, Rakuno Gakuen University, Ebetsu 069-8501, Japan \\ * Correspondence: h-iwano@rakuno.ac.jp; Fax: +81-11-388-4885 \\ + These authors contributed equally to this paper.
}

Received: 4 January 2018; Accepted: 19 February 2018; Published: 24 February 2018

\begin{abstract}
Antibiotic-resistant bacteria (ARB) have spread widely and rapidly, with their increased occurrence corresponding with the increased use of antibiotics. Infections caused by Staphylococcus aureus have a considerable negative impact on human and livestock health. Bacteriophages and their peptidoglycan hydrolytic enzymes (endolysins) have received significant attention as novel approaches against ARB, including S. aureus. In the present study, we purified an endolysin, Lys-phiSA012, which harbors a cysteine/histidine-dependent amidohydrolase/peptidase (CHAP) domain, an amidase domain, and a SH3b cell wall binding domain, derived from a polyvalent $S$. aureus bacteriophage which we reported previously. We demonstrate that Lys-phiSA012 exhibits high lytic activity towards staphylococcal strains, including methicillin-resistant S. aureus (MRSA). Analysis of deletion mutants showed that only mutants possessing the CHAP and SH3b domains could lyse $S$. aureus, indicating that lytic activity of the CHAP domain depended on the SH3b domain. The presence of at least $1 \mathrm{mM} \mathrm{Ca}^{2+}$ and $100 \mu \mathrm{M} \mathrm{Zn}^{2+}$ enhanced the lytic activity of Lys-phiSA012 in a turbidity reduction assay. Furthermore, a minimum inhibitory concentration (MIC) assay showed that the addition of Lys-phiSA012 decreased the MIC of oxacillin. Our results suggest that endolysins are a promising approach for replacing current antimicrobial agents and may contribute to the proper use of antibiotics, leading to the reduction of ARB.
\end{abstract}

Keywords: antibiotic resistant; multidrug resistant; antimicrobial agent; phage therapy; bacteriophage; endolysin; staphylococci; Staphylococcus aureus

\section{Introduction}

Antibiotic-resistant bacteria (ARB) have spread rapidly worldwide and are an important global health issue. ARB often result from the inappropriate use of antibiotics [1-3] and the occurrence of ARB is correlated with the amount of antibiotics used [4]. In the United States, about half of antibiotics are used to treat humans annually and the other half to treat livestock and for other agricultural applications [5]. Notably, antibiotics are administered to livestock for not only preventive and therapeutic approaches 
against infectious diseases, but also to improve growth [6]. Annual worldwide veterinary antibiotics (VA) use is now $10^{5}-10^{6}$ tones $[7,8]$. Several reports have suggested that antibiotics are used more heavily in livestock than in humans and VAs may be the largest source of ARB [9-11]. Indeed, transmission of ARB, such as methicillin-resistant Staphylococcus aureus (MRSA), by veterinary staff in contact with ARB carrier animals, and the potential role of the farm environment in the spread of ARB, have been reported [12-16], suggesting the environmental transfer of ARB from animals to humans.

ARBs that exhibit resistance to more than three classes of antibiotics are called multidrug-resistant bacteria (MDR). Staphylococcus aureus, an ESKAPE pathogen (Enterococcus faecium, Staphylococcus aureus, Klebsiella pneumoniae, Acinetobacter baumanii, Pseudomonas aeruginosa and Enterobacter spp.), is frequently isolated from clinical samples and is considered the major MDR. S. aureus has a considerable negative impact on human and veterinary medicine because the treatment of antibiotic-resistant $S$. aureus, including MRSA infections, are complicated due to the bacterium's multiple antibiotic-resistant mechanisms. In the veterinary field, mastitis caused by $S$. aureus negatively impacts milk production, leading to an economic loss of more than $\$ 100$ million annually in the United States and Japan $[17,18]$. S. aureus also is the most common pathogen causing chronic mastitis [19]. Furthermore, MRSA is spreading in hospitalized patients [20]. According to World Health Organization (WHO) reports, patients with MRSA are estimated to be $64 \%$ more likely to die compared with patients with non-resistant infections. A study by Lord O'Neill and colleagues, commissioned by the United Kingdom government, estimated that ARB would cause 10 million deaths each year by 2050 and will become a bigger risk than cancer [21,22]. Therefore, we face an unprecedented challenge from the emergence of ARB such as MRSA and MDR P. aeruginosa, putting humans and livestock at great risk. A novel alternative antimicrobial strategy is thus urgently required. Bacteriophages and bacteriophage enzyme-based approaches have potential as alternative tools for overcoming infectious diseases caused by ARB $[23,24]$.

Phage therapy, an alternative to classical antibiotic therapy, is receiving significant attention because bacteriophages are the most abundant organisms and infect bacteria specifically [24,25]. This allows their rapid and simple isolation from the environment and clinical application to kill pathogenic bacteria. We previously demonstrated that phage therapy is effective for treating equine keratitis caused by P. aeruginosa [26] and the lysis of antibiotic-resistant P. aeruginosa [27]. We also reported the isolation of a bacteriophage, phiSA012, and its wide host range towards various $S$. aureus strains [28] and its effective lytic capacity in a mouse mastitis model caused by S. aureus [29]. Challenges in the use of phage therapy have also been reported, such as the occurrence of phage-resistant bacteria, and horizontal gene transfer leading to increased bacterial virulence $[30,31]$.

Endolysins are peptidoglycan hydrolytic enzymes produced by bacteriophages and cleave cell wall peptidoglycan. Endolysins can thus target bacteria at the last stage of the lytic cycle using mechanisms different from those of antibiotics, and show cell lysis activity toward ARB such as S. aureus [23] and $P$. aeruginosa [32] in the absence of horizontal gene transfer. Interestingly, bacteria are unlikely to develop resistance towards endolysins $[33,34]$ because endolysins may cleave peptidoglycan sites essential for bacterial survival, and bacteriophages have developed highly efficient enzymes through evolution [35-37]. In addition, endolysins affect persisters, which are dormant bacteria showing high tolerance to antibiotics, and biofilms [38,39], and can be engineered to readily fuse with functional peptides [37]. Taken together, endolysins have enormous potential as a flexible tool for combatting ARB.

S. aureus bacteriophage endolysins such as Lys-phiK, Lys-GH15 and Lys-phiTwort have been isolated and investigated [40-42]. These endolysins are multidomain enzymes composed of a cysteine, histidine dependent amidohydrolase/peptidase (CHAP) domain at the N-terminus, an amidase (AMID) domain and a SH3b cell wall binding domain at the C-terminus and demonstrate high lytic activity toward S. aureus. The lytic efficacy and immune response of Lys-GH15 in vivo was previously reported $[41,43]$. In addition, the structures of three individual domains of Lys-GH15 were determined [44]. Notably, Lys-phiK is regarded as one of the best-characterized endolysins [23] and reveals a broad antimicrobial spectrum toward staphylococci isolated clinically from bovine and human [40]. It was reported that the Lys-phiK CHAP domain plays a critical role in the lysis of 
live staphylococcus and that lysis depends on the SH3b domain [45]. The crystal structure of the CHAP domain has been determined [46]. However, the properties of Lys-phiK related endolysins are not fully characterized. The aim of the present study was to demonstrate the possible preventive and therapeutic utility of efficient endolysins for clinical applications. To this end, we isolated and purified Lys-phiSA012, which has high amino acid sequence similarity with Lys-phiK, and studied the properties of Lys-phiSA012 lytic activity.

\section{Materials \& Methods}

\subsection{Bacterial Strains}

Bacterial strains used in the turbidity reduction assays, minimum inhibitory concentration (MIC) assay, and minimum bactericidal concentration (MBC) assay, are summarized in Table 1. The staphylococcal and streptococcal strains were grown at $37^{\circ} \mathrm{C}$ with aeration in lysogeny broth (LB) containing 2\% tryptone (Difco, Detroit, MI, USA), 0.5\% yeast extract (Difco) and Tod-Hewitt broth (THB) (Kanto Kagaku, Tokyo, Japan). Escherichia coli DH5 $\alpha$ and BL21(DE3) (Takara, Otsu, Japan) were grown at $37^{\circ} \mathrm{C}$ with aeration in LB medium for all subcloning. When needed, $100 \mu \mathrm{g} / \mathrm{mL}$ ampicillin was added to the LB medium (final concentration).

Table 1. Staphylococcal and streptococcal strains.

\begin{tabular}{|c|c|c|c|c|c|c|}
\hline $\begin{array}{l}\text { Bacterial } \\
\text { Strains }\end{array}$ & Name & \multicolumn{5}{|c|}{ Refarences and Remarks } \\
\hline $\begin{array}{l}\text { Staphylococcus } \\
\text { aureus }\end{array}$ & SA003 & \multicolumn{5}{|c|}{ Synnott, A.J. et al. [28], Iwano, H. et al. [29] } \\
\hline $\begin{array}{l}\text { Staphylococcus } \\
\text { pseudointermedius }\end{array}$ & StaP001 & \multirow{3}{*}{\multicolumn{5}{|c|}{ Field isolates identified by their 16s ribosomal RNA sequences. }} \\
\hline $\begin{array}{l}\text { Staphylococcus } \\
\text { haemolyticus }\end{array}$ & StaH001 & & & & & \\
\hline \multirow[t]{2}{*}{$\begin{array}{l}\text { Streptcoccus } \\
\text { agalactiae }\end{array}$} & StrA001 & & & & & \\
\hline & & Scc mec & MLST & spa type & Antimicrobial-resistance pattern & Refarences \\
\hline \multirow{6}{*}{ MRSA } & MRSA 2007-13 & II & NT & t002 & MPIPC, GM, KM, EM, OTC, ERFX & \multirow{4}{*}{ Ishihara, K. et al. [47] } \\
\hline & MRSA 2007-28 & II & NT & t1265 & MPIPC, KM, EM, & \\
\hline & MRSA 2007-57 & IV & NT & $\mathrm{t} 008$ & MPIPC, GM, KM, EM & \\
\hline & MRSA 2007-93 & II & NT & t062 & MPIPC, KM, EM, OTC, CP, ERFX & \\
\hline & MRSA VC39 Vet-1 & IV & ST380 & t021 & MPIPC, SM, KM, GM, EM & \multirow{2}{*}{$\begin{array}{c}\text { Ishihara, K. et al. } \\
{[48]}\end{array}$} \\
\hline & MRSA VC50 Vet-1 & IV & ST30 & $\mathrm{t} 1852$ & MPIPC, KM, GM, EM, CPFX & \\
\hline
\end{tabular}

MPIPC; oxacillin (breakpoint, $4 \mu \mathrm{g} / \mathrm{mL}), \mathrm{GM}$; gentamicin $(16 \mu \mathrm{g} / \mathrm{mL}), \mathrm{KM}$; kanamycin $(64 \mu \mathrm{g} / \mathrm{mL}), \mathrm{EM}$; erythromycin $(8 \mu \mathrm{g} / \mathrm{mL})$, OTC; oxytetracyclin $(32 \mu \mathrm{g} / \mathrm{mL})$, ERFX; enrofloxacin $(4 \mu \mathrm{g} / \mathrm{mL}), \mathrm{CP}$; chloramphenicol $(32 \mu \mathrm{g} / \mathrm{mL}) \mathrm{SM}$; streptomycin $(64 \mu \mathrm{g} / \mathrm{mL})$, CPFX; ciprofloxacin $(4 \mu \mathrm{g} / \mathrm{mL})$. Breakpoints were adopted according to the Clinical and Laboratory Standards Institute guidelines [49].

\subsection{Bacteriophage and Genome Analysis}

We previously reported the isolation of phiSA012 from a sewage treatment plant located in Tokyo (Japan) [28]. The genomic sequence of phiSA012 was published (NC_023573.1) and the endolysin amino acid sequence is available (YP_009006722). Protein sequence analysis and classification of Lys-phiSA012 were performed using InterPro to predict the domain architecture. The DNA of phiSA012 was isolated as described by Synnott et al. using a plate assay and centrifuged in polyethylene glycol 6000- $\mathrm{NaCl}$ [28]. PhiSA012 was then incubated in SNET buffer $(400 \mu \mathrm{g} / \mathrm{mL}$ ProteinaseK (Takara), $20 \mathrm{mM}$ Tris-HCl, $400 \mathrm{mM} \mathrm{NaCl}, 1 \%$ SDS, $5 \mathrm{mM}$ EDTA) at $55{ }^{\circ} \mathrm{C}$ overnight, phiSA012 DNA was extracted using phenol and chloroform, then purified by ethanol precipitation.

\subsection{Purification of Lys-phiSA012 Recombinant Protein}

The extracted phiSA012 DNA was used for subcloning of Lys-phiSA012. The endolysin gene was amplified with the primers Lys012-1Fw and Lys012-495Rv, as shown in Table 2. The amplified 
fragment was purified and subcloned into pGEX-6P-2 (GE, Buckinghamshire, UK) encoding a glutathione S-transferase (GST)-tag sequence at the C-terminal using an In-Fusion HD cloning kit (Clontech, Palo Alto, CA, USA), then the plasmid encoding Lys-phiSA012, pGEX-Lys012WT, was constructed. All subcloning was performed in E. coli DH5 $\alpha$. Plasmid construct accuracy was confirmed by DNA sequence analysis using a Big Dye Terminator V3.1 cycle sequencing kit (Applied Biosystems, Foster City, CA, USA) and an Applied Biosystems 3130 Genetic Analyzer. The cloned gene expression was performed as described elsewhere $[45,50]$ with slight modifications. In brief, the plasmid was used to transform E. coli BL21(DE3) and expression of the endolysin gene was induced by the addition of $0.1 \mathrm{mM}$ isopropyl- $\beta$-thiogalactopyranoside (final concentration) (Nacalai Tesque, Kyoto, Japan). Cells were incubated with shaking overnight at $25^{\circ} \mathrm{C}$ in a BIO-SHAKER BR-40LF (Taitec, Saitama, Japan). After centrifugation at $2300 \times \mathrm{g}$ for $5 \mathrm{~min}$ at $4{ }^{\circ} \mathrm{C}$, the supernatant was removed and $50 \mathrm{mM}$ Tris-HCl, $1 \mathrm{M} \mathrm{MgCl}_{2}$ and 10\% NP-40 (Wako, Osaka, Japan) were added to the pellet and the mixture was sonicated using a Bioruptor UCD-200 (Cosmo Bio, Tokyo, Japan). The mixture was centrifuged at $16,000 \times \mathrm{g}$ for $30 \mathrm{~min}$ at $4{ }^{\circ} \mathrm{C}$, then the supernatant containing soluble protein was purified using Econo-Pac ${ }^{\circledR}$ disposable chromatography columns (Bio-Rad Laboratories, Inc., Hercules, CA, USA) packed with glutathione Sepharose 4B (GE). The identity and concentration of the expressed protein was confirmed by sodium dodecyl sulfate polyacrylamide gel electrophoresis (SDS-PAGE). The obtained Lys-phiSA012 was stored at $-30{ }^{\circ} \mathrm{C}$ until use.

Table 2. Plasmids and primers.

\begin{tabular}{|c|c|c|c|c|}
\hline Plasmids & $\begin{array}{l}\text { Protein Produced } \\
\text { (Amino Acids) }\end{array}$ & Forward Primes & Reverse Primers & Recipient Vectors \\
\hline pGEX-Lys012WT & $1-495$ & Lys012-1Fw & Lys012-495Rv & pGEX-6P-2 \\
\hline pGEX-Lys012 $\Delta \mathrm{mt} 1$ & $161-495$ & Lys012-161Fw & Lys012-495Rv & pGEX-6P-2 \\
\hline \multirow[t]{3}{*}{ pGEX-Lys012 $\Delta \mathrm{mt} 2$} & $1-221,390-495$ & 1-221; Lys012-1Fw & 1-221; Lys012- $\Delta \mathrm{mt} 2 \mathrm{Rv}$ & pGEX-6P-2 \\
\hline & & 390-495; Lys012- $\Delta \mathrm{mt} 2 \mathrm{Fw}$ & 390-495; Lys012-495Rv & \\
\hline & & Overwrap; Lys012-1Fw & Overwrap; Lys012-495Rv & \\
\hline pGEX-Lys012 $\Delta \mathrm{mt} 2^{\prime}$ & $1-221$ & Lys012-1Fw & Lys012-221Rv & pGEX-6P-2 \\
\hline pGEX-Lys012 $\Delta \mathrm{mt} 3$ & $1-408$ & Lys012-1Fw & Lys012-408Rv & pGEX-6P-2 \\
\hline pGEX-Lys012 $\Delta \mathrm{mt} 4$ & $386-495$ & Lys012-386Fw & Lys012-495Rv & pGEX-6P-2 \\
\hline pGEX-Lys012 $\Delta \mathrm{mt} 5$ & $161-408$ & Lys012-161Fw & Lys012-408Rv & pGEX-6P-2 \\
\hline pGEX-Lys $012 \Delta \mathrm{mt} 6$ & $1-187$ & Lys012-1Fw & Lys012-187Rv & pGEX-6P-2 \\
\hline Primers & \multicolumn{4}{|c|}{ Sequences } \\
\hline Lys012-1Fw & \multicolumn{4}{|c|}{ 5'-TCCCCAGGAATTCCCATGGCTAAGACTCAAGCAGA-3' } \\
\hline Lys012-161Fw & \multicolumn{4}{|c|}{$5^{\prime}$-TCCCCAGGAATTCCCATGATACCTGTAAAAGCAGGAA-3' } \\
\hline Lys012-386Fw & \multicolumn{4}{|c|}{$5^{\prime}$-TCCCCAGGAATTCCCATGACAAGTAGCGCA-3' } \\
\hline Lys012-187Rv & \multicolumn{4}{|c|}{ 5'-CGCTCCAGTCGACCCCTATTTCTTTTTAGGTGCAG-3' } \\
\hline Lys012-221Rv & \multicolumn{4}{|c|}{ 5'-CGCTCGAGTCGACCCCTATGAAGAACGACCTGC-3' } \\
\hline Lys012-408Rv & \multicolumn{4}{|c|}{ 5'-CGCTAGTCGACCCCTAAGTTCCGTACTGGTTC-3' } \\
\hline Lys012-495Rv & \multicolumn{4}{|c|}{ 5'-CGCTCGAGTCGACCCCTACTTGAATACTCCCCAGG-3' } \\
\hline Lys012- $\Delta \mathrm{mt} 2 \mathrm{FW}$ & \multicolumn{4}{|c|}{$5^{\prime}$-CACAACGATGCAGGTCGTTCTTCAAGTACACCGGCAACTAGACCAGTTAC-3' } \\
\hline Lys012- $\Delta \mathrm{mt} 2 \mathrm{Rv}$ & \multicolumn{4}{|c|}{ 5'-GTAACTGGTCTAGTTGCCGGTGTACTTGAAGAACGACCTGCATCGTTGTG-3' } \\
\hline
\end{tabular}

Sequences complementary to linearized pGEX-6P-2 for In-fusion cloning are underlined.

\subsection{Generation of Domain(s) Deletion Mutants}

pGEX-Lys012WT was used for the construction of seven deletion mutant plasmids encoding a single domain or multiple domains of endolysin. Certain fragments of gene for Lys-phiSA012 were amplified with the primers summarized in Table 2. To construct pGEX-Lys012 $\Delta \mathrm{mt} 2$, two amplified fragments, corresponding to amino acids 1-221 and 390-495, were used for overwrap PCR using Lys012-1Fw and Lys012-495Rv primers. The amplified fragments were subcloned into pGEX-6P-2 and each protein was purified as described above. 


\subsection{Turbidity Reduction Assays}

The lytic activity of Lys-phiSA012 and each deletion mutant protein was assessed using turbidity reduction assays as described by Becker et al. [45] and Son et al. [51], with some modifications. In brief, staphylococcal strains and streptococcal strains were grown in LB medium or THB medium at $37{ }^{\circ} \mathrm{C}$ to an $\mathrm{OD}_{600}$ of 1.0 . Each culture was centrifuged at $2300 \times \mathrm{g}$ for $5 \mathrm{~min}$ at $4{ }^{\circ} \mathrm{C}$ and the cells were resuspended in $2 \times$ LB medium, then stored on ice until use. Turbidity reduction assays were initiated by adding the same amount of purified Lys-phiSA012 or each domain(s) deletion mutant, then the $\mathrm{OD}_{600}$ value was monitored using a plate reader (Sunrise Rainbow Thermos RC, TECAN Austria GmbH, Salzburg, Austria). To evaluate the effect of $\mathrm{Ca}^{2+}$ and $\mathrm{Zn}^{2+}$ on endolysin lytic activity, SA003 was prepared as described above. After centrifugation at $2300 \times g$ for $5 \mathrm{~min}$ at $4{ }^{\circ} \mathrm{C}$, the cells were resuspended in TBS $(50 \mathrm{mM}$ Tris- $\mathrm{HCl}, 138 \mathrm{mM} \mathrm{NaCl}, 2.7 \mathrm{mM} \mathrm{KCl}$ ) buffer with $\mathrm{CaCl}_{2}(0 \mu \mathrm{M}, 1 \mu \mathrm{M}, 10 \mu \mathrm{M}, 100 \mu \mathrm{M}, 1 \mathrm{mM}, 2.5 \mathrm{mM}, 5 \mathrm{mM})$ or $\mathrm{ZnCl}_{2}(0 \mu \mathrm{M}, 1 \mu \mathrm{M}, 10 \mu \mathrm{M}, 100 \mu \mathrm{M}$, $500 \mu \mathrm{M}, 1 \mathrm{mM}, 2.5 \mathrm{mM})$. The $\mathrm{OD}_{600}$ value was monitored with incubation using the plate reader after the addition of Lys-phiSA012.

\subsection{MIC and MBC Assays}

MIC and MBC assays were performed as described previously [45,52] with some modifications. The MIC values of oxacillin with or without Lys-phiSA012 towards SA003 were determined in 96-well plates. Each plate incubated serial 2-fold dilution of oxacillin and Lys-phiSA012 using LB medium overnight at $37{ }^{\circ} \mathrm{C}$ at concentrations ranging from 64 to $0 \mu \mathrm{g} / \mathrm{mL}$ and from 2.0 to $0 \mu \mathrm{g} / \mathrm{mL}$, respectively. Overnight incubation was initiated by adding $10 \mu \mathrm{L}$ SA003 to each well of the 96-well plate that also contained $100 \mu \mathrm{L}$ LB medium. The MBC values of Lys-phiSA012 towards SA003 with 25\% glycerol were determined using LB medium after overnight incubation at $37{ }^{\circ} \mathrm{C}$. After the MIC assay of Lys-phiSA012 with $25 \%$ glycerol, $10 \mu \mathrm{L}$ of liquid from each well in the 96-well plate was transferred to a fresh 96-well plate containing $100 \mu \mathrm{L}$ antimicrobial agent free LB medium. The MIC and MBC values were evaluated by visual inspection after overnight incubation. MIC and MBC assays of glycerol were also performed using the same methods.

\subsection{Bioinformatics Analysis}

Amino acid sequences for multiple alignment and protein structure homology modeling were obtained from the National Center for Biotechnology Information (NCBI) database. Multiple alignment analysis between endolysin sequences was performed using GENETYX software v.10. The 3D protein structure models of the cysteine, histidine dependent amidohydrolases/peptidases (CHAP) and amidase (AMID) domain on Lys-phiSA012 were constructed and analyzed with modeling by homology to the existing crystal structure using the SWISS-MODEL server [53-56]. Homologous proteins and amino acid sequence alignments are summarized in Table 3 and Supplementary Materials Figure S1. A BLAST search was performed using the nucleotide sequence of Lys-phiK obtained from NCBI database as a query sequence. Endolysins which revealed over $90 \%$ query cover and identity are summarized in Table 4. 
Table 3. Protein structure modeling information.

\begin{tabular}{|c|c|c|c|c|c|c|}
\hline & Homologous Protein & Source Organism & Residues & Protein ID in PDBe & Seq. Identity & Ligands \\
\hline Lys-phiSA012 CHAP & $\begin{array}{c}\text { ORF30/31 } \\
\text { CHAP domain }\end{array}$ & $\begin{array}{c}\text { Staphylococcus virus K } \\
\text { (Gene name: PhageK_071) }\end{array}$ & $1-165$ & $4 \mathrm{ct} 3.1$ & $99.39 \%$ & $\begin{array}{l}\mathrm{Ca}^{2+} \\
\mathrm{Cl}^{-} \\
\mathrm{Hg}^{2+}\end{array}$ \\
\hline Lys-phiSA012 AMID & $\begin{array}{c}\text { Endolysin } \\
N \text {-acetylmuramoyl-L-alanine amidase }\end{array}$ & $\begin{array}{l}\text { Staphylococcus phage GH15 } \\
\text { (Gene name: GH15_071) }\end{array}$ & $165-403$ & 4ols & $100 \%$ & $\begin{array}{c}\mathrm{Zn}^{2+} \\
\mathrm{Mg}^{2+} \\
\mathrm{Fe}^{3+}\end{array}$ \\
\hline
\end{tabular}

Table 4. LysK-like endolysins.

\begin{tabular}{|c|c|c|c|c|c|c|c|c|c|c|c|c|c|c|c|c|c|c|c|c|c|c|c|c|c|c|c|}
\hline \multirow{2}{*}{ Source of Endolysin } & \multirow{2}{*}{$\begin{array}{l}\text { Query Cover } \\
\text { (Nucleotide) }\end{array}$} & \multirow{2}{*}{$\begin{array}{c}\text { Identity } \\
\text { (Nucleotide) }\end{array}$} & \multirow{2}{*}{ Accession } & \multicolumn{23}{|c|}{ Resideu at Position (Amino Asid) } & \multirow{2}{*}{$\begin{array}{c}\text { Identity } \\
\text { (Amino Acid) }\end{array}$} \\
\hline & & & & 26 & 48 & 83 & 107 & 109 & 113 & 165 & 231 & 300 & 372 & 380 & 383 & 406 & 414 & 425 & 437 & 452 & 453 & 470 & 484 & 485 & 486 & 493 & \\
\hline Bacteriophage K & $100 \%$ & $100 \%$ & AY176327.1 & $\mathrm{V}$ & G & $\mathrm{s}$ & $\mathrm{F}$ & $\mathrm{s}$ & $\mathrm{E}$ & A & $\mathrm{N}$ & $\mathrm{A}$ & $\mathrm{D}$ & $\mathrm{V}$ & $\mathrm{D}$ & $\mathrm{Y}$ & $\mathrm{N}$ & $\mathrm{V}$ & $\mathrm{V}$ & $\mathrm{V}$ & $\mathrm{C}$ & $\mathrm{N}$ & $\mathrm{N}$ & Q & $\mathrm{I}$ & $\mathrm{V}$ & $100.00 \%$ \\
\hline Bacteriophage JD007 & $100 \%$ & $99 \%$ & JX878671.1 & $\mathrm{V}$ & G & $\mathrm{s}$ & $\mathrm{F}$ & $\mathrm{s}$ & $\mathrm{E}$ & A & $\mathrm{N}$ & A & $\mathrm{D}$ & $\mathrm{V}$ & D & $\mathrm{Y}$ & $\mathrm{N}$ & $\mathrm{V}$ & $\mathrm{V}$ & $\mathrm{V}$ & C & $\mathrm{N}$ & $\mathrm{N}$ & $\mathrm{Q}$ & I & $\mathrm{V}$ & $100.00 \%$ \\
\hline Bacteriophage SA012 & $100 \%$ & $99 \%$ & AB903967.1 & $\mathrm{V}$ & G & $\mathrm{N}$ & $\mathrm{F}$ & $\mathrm{s}$ & E & A & $\mathrm{N}$ & A & $\mathrm{D}$ & $\mathrm{V}$ & D & $\mathrm{Y}$ & $\mathrm{N}$ & $\mathrm{V}$ & $\mathrm{V}$ & $\mathrm{V}$ & C & $\mathrm{N}$ & $\mathrm{N}$ & $\mathrm{Q}$ & I & $\mathrm{V}$ & $99.80 \%$ \\
\hline Bacteriophage vB_Sau_CG & $100 \%$ & $99 \%$ & KY794641.1 & $\mathrm{V}$ & G & $\mathrm{N}$ & $\mathrm{F}$ & $\mathrm{s}$ & $\mathrm{Q}$ & A & $\mathrm{T}$ & A & $\mathrm{D}$ & $\mathrm{V}$ & $\mathrm{D}$ & Y & $\mathrm{N}$ & $\mathrm{V}$ & $\mathrm{V}$ & $\mathrm{V}$ & $\mathrm{C}$ & $\mathrm{N}$ & $\mathrm{N}$ & $\mathrm{Q}$ & I & $\mathrm{v}$ & $99.39 \%$ \\
\hline Bacteriophage S25-3 & $100 \%$ & $99 \%$ & AB853330.1 & $\mathrm{V}$ & G & $\mathrm{N}$ & $\mathrm{F}$ & $\mathrm{s}$ & $\bar{E}$ & E & $\mathrm{N}$ & $\mathrm{T}$ & $\mathrm{D}$ & $\mathrm{V}$ & $\mathrm{D}$ & Y & $\mathrm{N}$ & $\mathrm{v}$ & $\mathrm{V}$ & $\mathrm{V}$ & $\mathrm{C}$ & $\mathrm{N}$ & $\mathrm{N}$ & $\mathrm{Q}$ & I & $\mathrm{v}$ & $99.39 \%$ \\
\hline Bacteriophage S25-4 & $100 \%$ & $99 \%$ & AB853331.1 & $\mathrm{V}$ & G & $\mathrm{N}$ & $\mathrm{F}$ & $\mathrm{s}$ & $\mathrm{E}$ & $\mathrm{E}$ & $\mathrm{N}$ & $\mathrm{T}$ & $\mathrm{D}$ & $\mathrm{V}$ & $\mathrm{D}$ & $\mathrm{Y}$ & $\mathrm{N}$ & $\mathrm{V}$ & $\mathrm{V}$ & $\mathrm{V}$ & $\mathrm{C}$ & $\mathrm{N}$ & $\mathrm{N}$ & $\mathrm{Q}$ & I & $\mathrm{v}$ & $99.39 \%$ \\
\hline Bacteriophage SA3 & $100 \%$ & $96 \%$ & MF001365.1 & I & G & $\mathrm{s}$ & $\mathrm{F}$ & $\mathrm{s}$ & Q & A & $\mathrm{N}$ & A & $\mathrm{D}$ & $\mathrm{V}$ & D & $\mathrm{Y}$ & $\mathrm{N}$ & $\mathrm{V}$ & $\mathrm{V}$ & $\mathrm{V}$ & C & $\mathrm{N}$ & $\mathrm{N}$ & $\mathrm{H}$ & I & $\mathrm{V}$ & $99.39 \%$ \\
\hline Bacteriophage qdsa002 & $100 \%$ & $96 \%$ & KY779849.1 & I & G & $\mathrm{s}$ & $\mathrm{F}$ & $\mathrm{s}$ & $\mathrm{Q}$ & A & $\mathrm{N}$ & A & D & $\mathrm{V}$ & D & $\mathrm{Y}$ & $\mathrm{N}$ & $\mathrm{V}$ & $\mathrm{V}$ & $\mathrm{V}$ & C & $\mathrm{N}$ & $\mathrm{N}$ & $\mathrm{H}$ & I & $\mathrm{v}$ & $99.39 \%$ \\
\hline Bacteriophage GH15 & $100 \%$ & $96 \%$ & JQ686190.1 & I & G & s & $\mathrm{F}$ & $\mathrm{s}$ & $\mathrm{Q}$ & A & $\mathrm{N}$ & A & $\mathrm{D}$ & $\mathrm{V}$ & $\mathrm{D}$ & $\mathrm{Y}$ & $\mathrm{N}$ & $\mathrm{V}$ & $\mathrm{V}$ & $\mathrm{V}$ & $\mathrm{C}$ & D & $\mathrm{N}$ & $\mathrm{H}$ & I & $\mathrm{V}$ & $99.19 \%$ \\
\hline Bacteriophage vB_Sau_Clo6 & $100 \%$ & $94 \%$ & KY794642.1 & $\mathrm{V}$ & $\mathrm{K}$ & $\mathrm{N}$ & $\mathrm{Y}$ & E & E & A & $\mathrm{K}$ & A & $\mathrm{N}$ & $\mathrm{V}$ & $\mathrm{K}$ & $\mathrm{Y}$ & $\mathrm{N}$ & $\mathrm{V}$ & $\mathrm{V}$ & I & C & $\mathrm{D}$ & $\mathrm{s}$ & $\mathrm{Y}$ & $\mathrm{T}$ & I & $97.98 \%$ \\
\hline Bacteriophage vB_Sau_S24 & $100 \%$ & $94 \%$ & KY794643.1 & $\mathrm{V}$ & $\mathrm{K}$ & $\mathrm{N}$ & $\mathrm{Y}$ & $\mathrm{E}$ & $\mathrm{E}$ & A & $\mathrm{K}$ & A & $\mathrm{N}$ & $\mathrm{V}$ & $\mathrm{K}$ & $\mathrm{Y}$ & $\mathrm{N}$ & $\mathrm{V}$ & $\mathrm{V}$ & $\mathrm{V}$ & A & $\mathrm{N}$ & $\mathrm{N}$ & $\mathrm{Q}$ & $\mathrm{V}$ & $\mathrm{T}$ & $97.37 \%$ \\
\hline Bacteriophage MCE-2014 & $99 \%$ & $99 \%$ & KJ888149.1 & $\mathrm{V}$ & G & $\mathrm{S}$ & $\mathrm{F}$ & $\mathrm{S}$ & $\mathrm{E}$ & A & $\mathrm{N}$ & A & $\mathrm{D}$ & $\mathrm{V}$ & D & $\mathrm{Y}$ & $\mathrm{N}$ & $\mathrm{V}$ & $\mathrm{V}$ & $\mathrm{V}$ & C & $\mathrm{N}$ & $\mathrm{s}$ & $\hat{\mathrm{H}}$ & $\mathrm{V}$ & $\mathrm{V}$ & $99.39 \%$ \\
\hline \multirow[t]{2}{*}{ Bacteriophage IPLA-RODI } & $99 \%$ & $95 \%$ & КР027446.1 & I & G & $\mathrm{s}$ & $\mathrm{F}$ & $\mathrm{s}$ & Q & A & $\mathrm{N}$ & A & $\mathrm{D}$ & I & $\mathrm{D}$ & $\mathrm{F}$ & $\mathrm{s}$ & $\mathrm{I}$ & $\mathrm{I}$ & $\mathrm{V}$ & $\mathrm{C}$ & $\mathrm{N}$ & $\mathrm{N}$ & $\mathrm{H}$ & $\mathrm{I}$ & $\mathrm{v}$ & $98.38 \%$ \\
\hline & & & & & & & CHAP & & & & & & midas & & & & & & $\mathrm{SH}$ & & & & & & & & \\
\hline
\end{tabular}

Amino acid changes compared to Lys-phiK are indicated in blue (Lys-phiSA012) or yellow (other). 


\subsection{Statistical Analysis}

Statistical analysis was conducted using the Tukey-Kramer test based on one-way ANOVA from three independent experiments. Statistically significant differences are indicated by asterisks ${ }^{*}: p<0.05$, **: $p<0.01)$ or crosses $\left({ }^{\dagger}: p<0.05\right)$.

\section{Results}

\subsection{Lytic Activity and the Antimicrobial Spectrum of Lys-phiSA012.}

The endolysin of phiSA012, Lys-phiSA012, is encoded in ORF51 and is composed of 495 amino acids. The conserved domain of Lys-phiSA012 was shown by bioinformatics analysis to be a cysteine, histidine dependent amidohydrolase/peptidase (CHAP) domain at the N-terminus encompassing amino acid residues 29-160, an amidase (AMID) domain encompassing amino acid residues 188-385, and a SH3b cell wall binding domain at the C-terminus encompassing amino acid residues 409-481 (Figure 1).

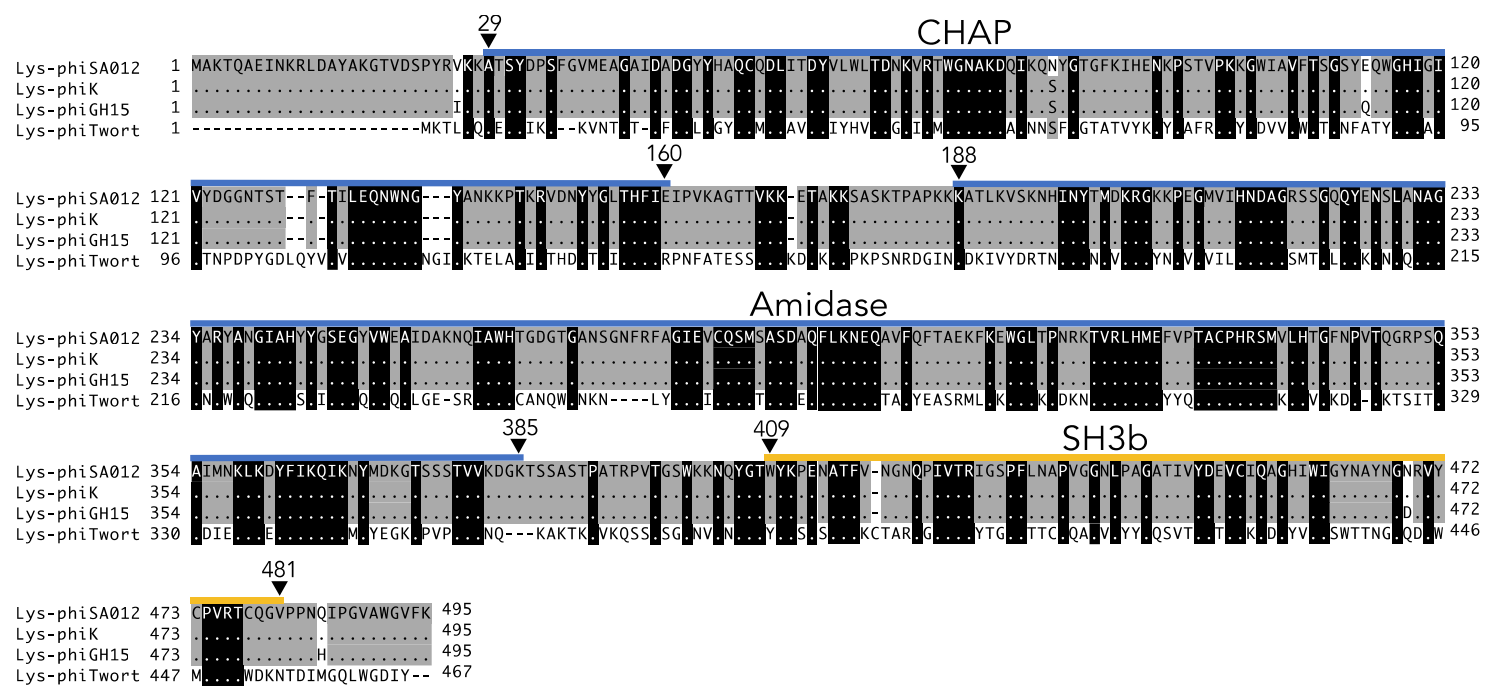

Figure 1. Prediction of the domain architecture and multiple alignment analysis of Lys-phiSA012. Lys-phiSA012 is composed of a CHAP, AMID, and SH3b domain. The amino acid sequence of Lys-phiSA012 was analyzed using InterPro. Blue and yellow lines indicate the domain structure of Lys-phiSA012. Multiple alignment analysis of the full length endolysins Lys-phiSA012, Lys-phiK, Lys-phiGH15, and Lys-phiTwort. Identical residues are shown as dots and amino acid residues conserved between the four endolysins are highlighted by a black $(100 \%)$ or gray $(80 \%)$ scale.

Comparison of the amino acid sequences of Lys-phiSA012 with the characterized Staphylococcus endolysins, Lys-phiK, Lys-phiGH15, and Lys-phiTwort, revealed that Lys-phiSA012 has high amino acid sequence similarity with Lys-phiK $(99.80 \%)$ and Lys-phiGH15 $(98.99 \%)$, but not with Lys-phiTwort (44.54\%) (Figure 1). Furthermore, endolysins which have high nucleotide sequence similarity with Lys-phiK (LysK-like eondolysins) were found by a BLAST search, as summarized in Table 4; however, the lytic capabilities of LysK-like endolysins (with the exception of Lys-GH15) remain poorly characterized. Previous reports have focused on the lytic capabilities of the bacteriophages vB_Sau_CG, vB_Sau_Clo6, vB_Sau_S24 [57], S25-3 [58], MCE-2014 [59] and IPLA-RODI [60], from which the LysK-like endolysins are derived, or only genome sequences of bacteriophages JD007, S25-4, SA3 and qdsa002 have been registered. Therefore, we initially produced Lys-phiSA012WT and performed turbidity reduction assays to confirm the lytic activity of Lys-phiSA012. As shown in Figure 2A, Lys-phiSA012 showed high lytic activity towards SA003 (A schematic of the produced Lys-phiSA012WT protein and SDS-PAGE analysis of the purified protein are shown in Figure 3A,B). 
Broad lytic activity of phiSA012 and Lys-phiK has been reported [28,40]. To determine whether Lys-phiSA012 similarly has lytic activity beyond S. aureus, we examined the antimicrobial spectrum of Lys-phiSA012 towards staphylococcal strains and Streptococcus agalactiae. Lys-phiSA012 showed high antimicrobial activity towards not only SA003, but also StaP001 and StaH001 as expected. In addition, the $\mathrm{OD}_{600}$ was reduced within a few minutes of adding Lys-phiSA012, with an initial $\mathrm{OD}_{600}$ of $0.4-0.6$ being reduced to $\mathrm{OD}_{600}<0.2$ over $10 \mathrm{~min}$ (Figure 2A-C).
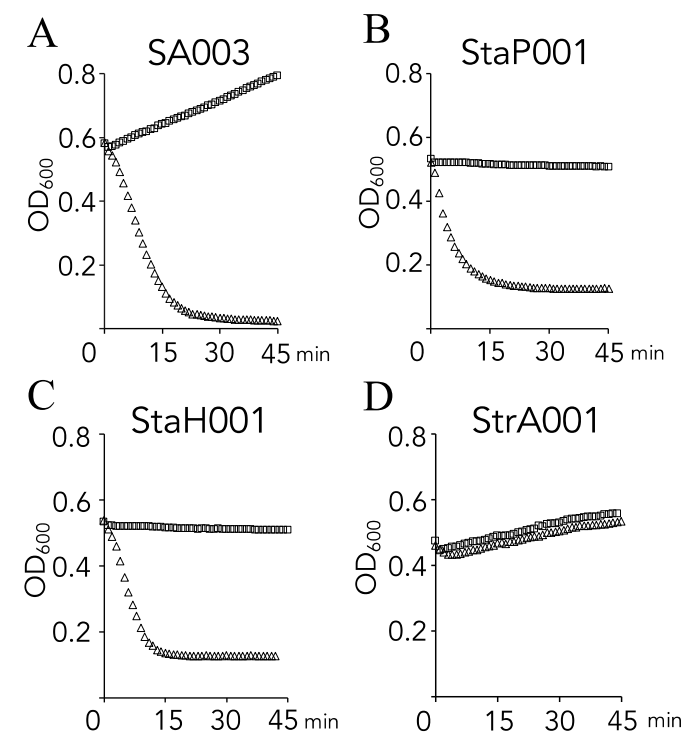

$\mathrm{E}$

$\triangle$ with Lys-phiSA012 $\square$ without Lys-phiSA012

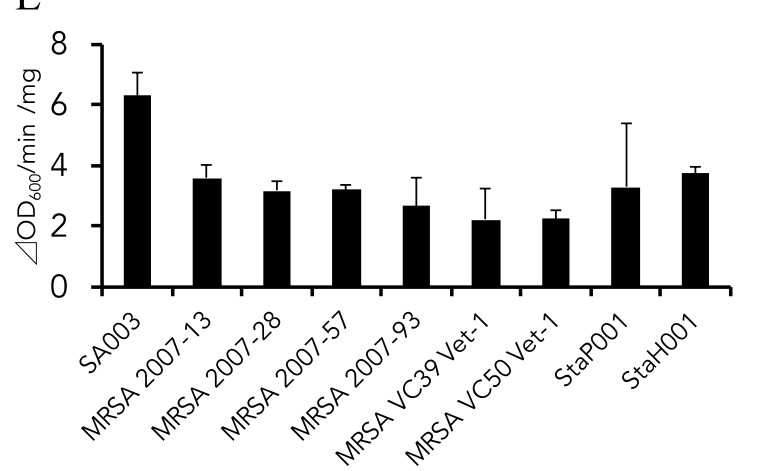

Figure 2. Antimicrobial spectrum of Lys-phiSA012. Lytic activities towards SA003, StaP, StaH, StrA and MRSA were examined using a turbidity reduction assay, as described in the materials and methods section. SA003 was isolated from bovine milk and has been reported to be susceptible to phiSA012 [28]. SA003 was also used in a mouse mastitis model [29]. MRSA strains were isolated from veterinarians and staff members of veterinary clinics [48,49]. Lys-phiSA012 (A) $109 \mu \mathrm{g} / \mathrm{mL}$, (B) $132 \mu \mathrm{g} / \mathrm{mL}$, (C) $132 \mu \mathrm{g} / \mathrm{mL}$ and (D) $106 \mu \mathrm{g} / \mathrm{mL}$ was added to the bacterial cultures. The values of $\mathrm{OD}_{600}$ were plotted each minute. (E) Lytic activities towards staphylococcal strains were examined. The maximum rate for each reaction is represented as $\Delta \mathrm{OD}_{600} \mathrm{~min}^{-1} \mathrm{mg}^{-1}$, calculated as previously reported [61] and presented as means \pm standard deviation (SD).

However, Lys-phiSA012 could not lyse StrA001, as shown by the turbidity reduction assay, and the initial $\mathrm{OD}_{600}$ increased with increasing incubation time (Figure 2D). We next assessed the antimicrobial activity of Lys-phiSA012 towards MRSA strains resistant against more than four antibiotics (Table 1). The turbidity reduction assay showed lytic activity of Lys-phiSA012 towards six MRSA strains (Figure 2E). The maximum rate for the lysis of SA003 $\left(\Delta \mathrm{OD}_{600} \mathrm{~min}^{-1} \mathrm{mg}^{-1}\right)$ was higher than that for the other strains. 


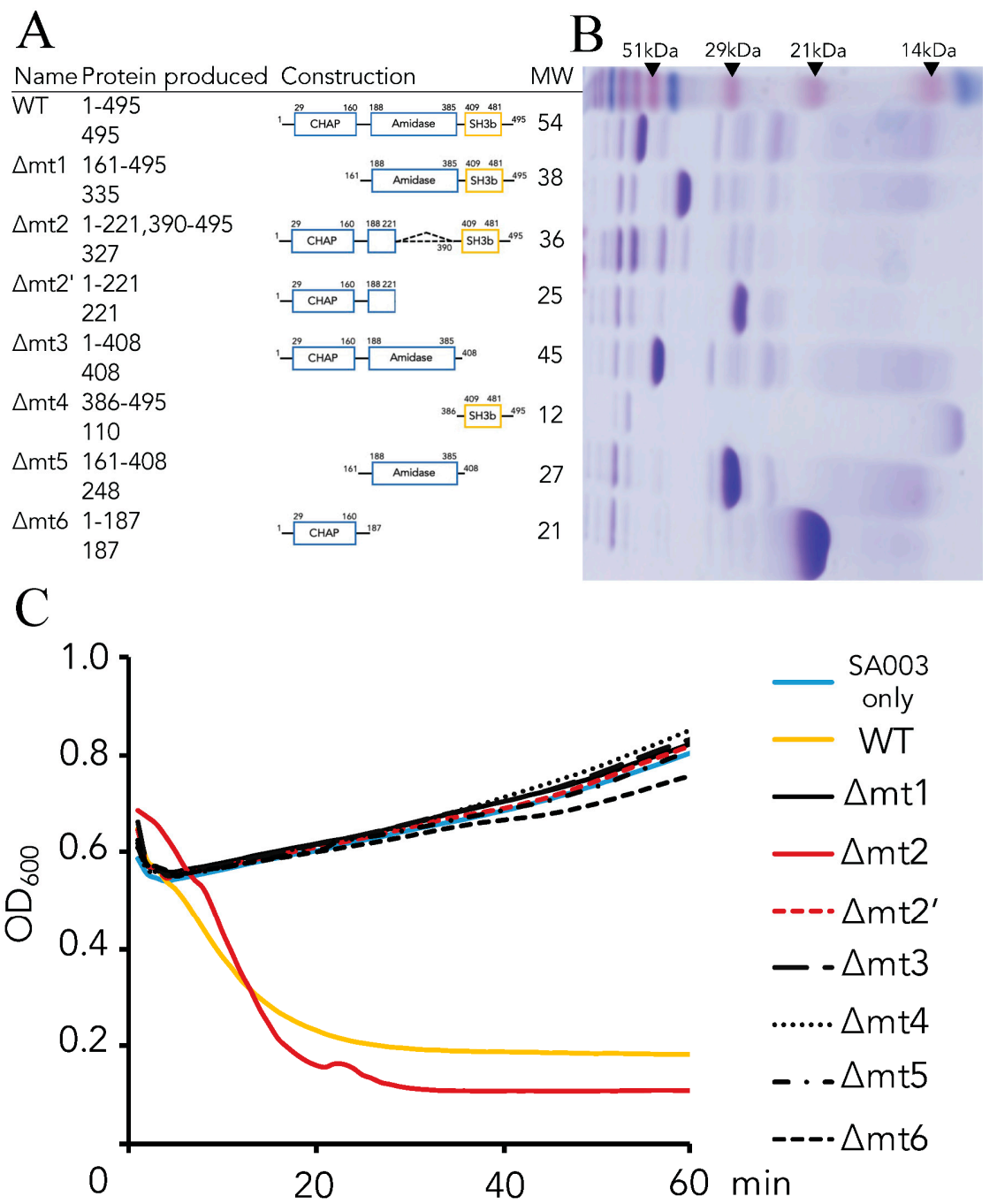

Figure 3. Schematic representation of Lys-phiSA012 and domain(s) deletion mutants and their lytic activities towards SA003. (A) Schematic representation of the Lys-phiSA012 protein construct. Amino acid residues 29-160: CHAP domain, 188-385: AMID domain, 409-481: SH3b domain. (B) SDS-PAGE of purified Lys-phiSA012 and each domain(s) deletion mutant, performed using $15 \%$ polyacrylamide gel. Upper lane; Standard molecular weight markers. (C) Lytic activities of Lys-phiSA012 and each domain(s) deletion mutant towards SA003. Except for $\Delta \mathrm{mt} 2,163.8 \mathrm{pmol}$ of the endolysin was added to the culture medium. For $\Delta \mathrm{mt} 2,45.98 \mathrm{pmol}$ was added.

\subsection{Critical Region of the Lys-phiSA012 Protein Required for Lytic Activity}

Next, we constructed plasmids encoding Lys-phiSA012 domain(s) deletion mutants to clarify the region of Lys-phiSA012 constructs critical for lytic activity towards SA003. The purified proteins were identified by SDS-PAGE analysis (Figure 3B). Turbidity reduction assays using the domain(s) deletion mutants clearly demonstrated that Lys-phiSA012 $\Delta \mathrm{mt} 2$ showed high lytic activity similar to Lys-phiSA012WT (Figure 3C) whereas the other mutants showed no lytic activity towards SA003.

\subsection{Optimal $\mathrm{Ca}^{2+}$ and $\mathrm{Zn}^{2+}$ Concentration for the Lytic Activity of Lys-phiSA012}

Deletion analysis demonstrated that a CHAP domain and a SH3b domain play important roles for lytic activity. Enhancement of the lytic activity of endolysins by ions was previously reported $[45,50]$. Therefore, we next investigated the presence of an ion binding site in the Lys-phiSA012 catalytic domains. 3D models of the CHAP and AMID domain structures were constructed using the 
SWISS-MODEL server. The homologous proteins used in structure modeling are summarized in Table 3 and the model-template alignment is shown in Figure A1.

The constructed model of the CHAP domain revealed that $\mathrm{Ca}^{2+}$ is bound in the $\mathrm{N}$-terminal region and interacts with the side chains of Asp45, Asp47, Tyr49, His51 and Asp56 (Figure 4A). In addition, $\mathrm{Cl}^{-}$and $\mathrm{Hg}^{2+}$ were indicated as bound ligands for the CHAP domain (Table 3). The constructed model of the AMID domain showed that $\mathrm{Zn}^{2+}$ is bound in the center of the domain and interacts with the side chains of His214, His324 and Cys332 (Figure 4B), and $\mathrm{Mg}^{2+}$ and $\mathrm{Fe}^{3+}$ were indicated as bound ligands for the AMID domain (Table 3). As shown in Figure 4C, no amino acid changes were observed in LysK-like endolysins at the $\mathrm{Ca}^{2+}$ and $\mathrm{Zn}^{2+}$-binding site residues or at the CHAP active site residues of Lys-phiK [62].

A

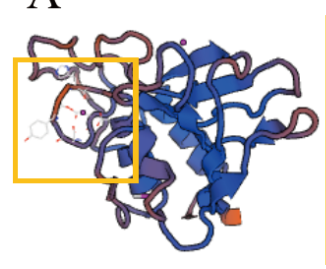

B

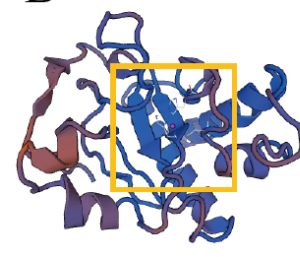

$\mathrm{C}$
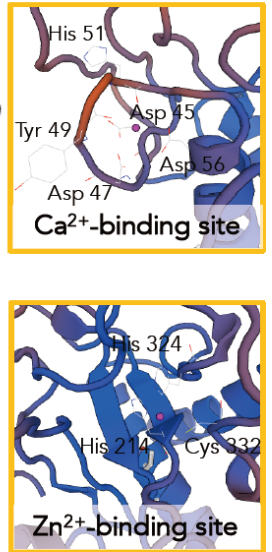

$\mathrm{D}$

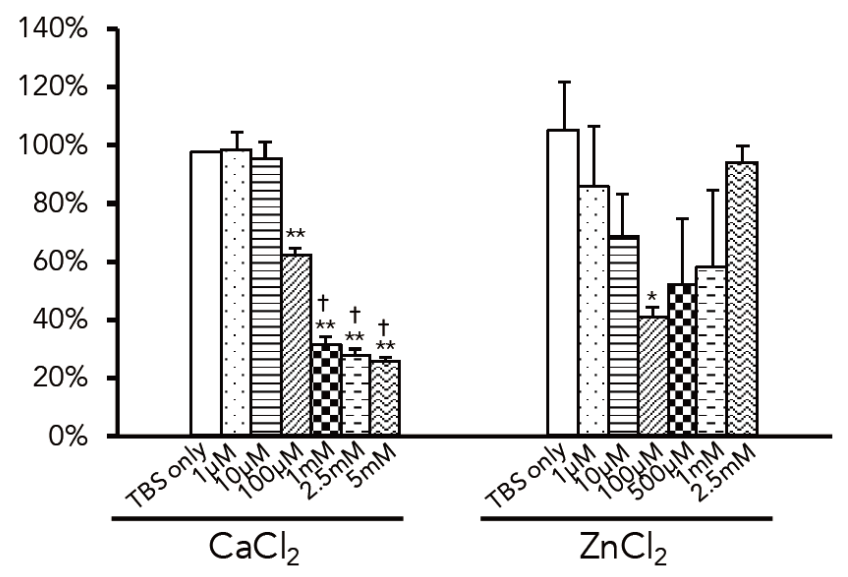
vB_Sau_Clo6 $\frac{\text { vB_Sau_S24 }}{\text { Phe107Tyr }}$ Asp45 Asp47 Tyr49 His51 Cys54 Asp56 Phe107Tyr

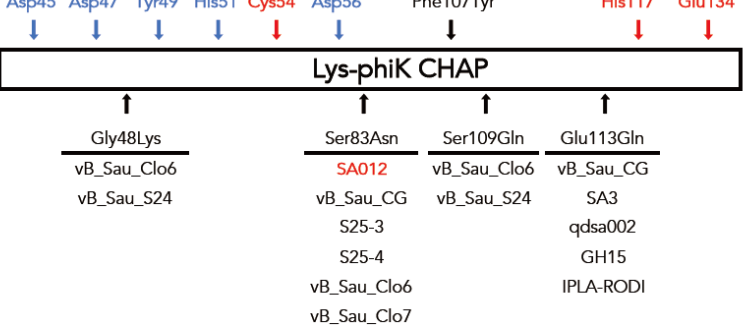

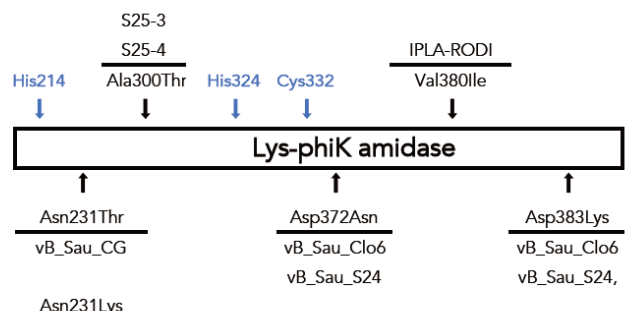

Figure 4. Protein structure modeling of the CHAP and AMID domains, and the effects of $\mathrm{Ca}^{2+}$ and $\mathrm{Zn}^{2+}$ on the lytic activity of Lys-phiSA012. Protein structure models of (A) the CHAP and (B) AMID domains in Lys-phiSA012. The models were constructed using the SWISS-MODEL server and the homologous proteins used for protein structure modeling are summarized in Table 3. Detailed views of the $\mathrm{Ca}^{2+}$ and $\mathrm{Zn}^{2+}$ coordination sites are framed in yellow. The $\mathrm{Ca}^{2+}$-binding site is composed of Asp45, Asp47, Tyr49, His51 and Asp56. The $\mathrm{Zn}^{2+}$-binding site is composed of His214, His324 and Cys332. Ions are shown as pink spheres. (C) Schematic image of the CHAP and AMID domain of Lys-phiK. Blue arrows indicate the amino acid residues which contacts with $\mathrm{Ca}^{2+}$ and $\mathrm{Zn}^{2+}$. Red arrows indicate the active site residues of the CHAP domain. Black arrows indicate the amino acid changes in LysK-like endolysins summarized in Table 4. Bacteriophages whose endolysins are related to Lys-phiK are also indicated. Lys-phiSA012 differs by single amino acid residue from Lys-phiK, Ser83Asn on a CHAP domain. (D) The effects of $\mathrm{Ca}^{2+}$ and $\mathrm{Zn}^{2}$ on the lytic activity of Lys-phiSA012 were analyzed using a turbidity reduction assay as described in the materials and methods section. Data are shown as relative $\mathrm{OD}_{600}$ reduction rate (initial OD600 divided by OD600 $60 \mathrm{~min}$ after adding Lys-phiSA012). The values represent means \pm SD. Significance was analyzed by the Tukey-Kramer test based on one-way ANOVA and is indicated by asterisks compared to TBS alone $\left(^{*}: p<0.05,{ }^{* *}: p<0.01\right)$ or crosses against $100 \mu \mathrm{M}$ $\mathrm{Ca}^{2+}\left({ }^{+}: p<0.05\right)$. 
It was reported that $\mathrm{Zn}^{2+}$ inhibits the Lys-phiK activity and that $\mathrm{Ca}^{2+}$ enhances the stability of Lys-phiK but has no effect on lytic activity [63]. However, ions in the Lys-phiK buffer were not removed in those assays. Sanz-Gaitero et al. also commented on this point and suggested that $\mathrm{Zn}^{2+}$ might play a regulatory role [46]. Therefore, we examined the effects of $\mathrm{Ca}^{2+}$ and $\mathrm{Zn}^{2+}$ on the lytic activity of Lys-phiSA012 to determine the optimal $\mathrm{Ca}^{2+}$ and $\mathrm{Zn}^{2+}$ concentrations. Turbidity reduction assays were performed in the presence and absence of $\mathrm{Ca}^{2+}$ or $\mathrm{Zn}^{2+}$ in TBS buffer. The addition of $\mathrm{Ca}^{2+}$ significantly reduced the $\mathrm{OD}_{600}$ in a dose dependent manner. Notably, a high concentration of $\mathrm{Ca}^{2+}$ (above $1 \mathrm{mM}$ ) significantly increased Lys-phiSA012 activity compared to the addition of $100 \mu \mathrm{M} \mathrm{Ca}^{2+}$ (Figure 4C). Lys-phiSA012 exhibited no lytic activity in the absence of $\mathrm{Ca}^{2+}$ and the $\mathrm{OD}_{600}$ value did not change from the initial value of $\mathrm{OD}_{600}$ 0.6. The addition of $100 \mu \mathrm{M} \mathrm{Zn}^{2+}$ resulted in a significant decrease in $\mathrm{OD}_{600}$ compared to TBS alone; interestingly, however, the addition of $1 \mu \mathrm{M} \mathrm{Zn}^{2+}$ did not enhance the lytic activity of Lys-phiSA012 compared to TBS alone. We further examined whether divalent ions in LB medium affect lytic activity. Lys-phiSA012 in LB medium containing $10 \mu \mathrm{M}$ EGTA did not inhibit the growth of SA003 (Figure A2).

\subsection{MIC Assays of Oxacillin w/wo Lys-phiSA012}

The MIC of oxacillin towards SA003 with or without (w/wo) Lys-phiSA012 was determined to confirm whether Lys-phiSA012 acts cooperatively with antibiotics due to the different mechanisms underlying the antimicrobial activities of endolysins and antibiotics. The oxacillin MIC without Lys-phiSA012 was $\geq 32 \mu \mathrm{g} / \mathrm{mL}$, whereas the addition of $1.0 \mu \mathrm{g} / \mathrm{mL}$ or $2.0 \mu \mathrm{g} / \mathrm{mL}$ Lys-phiSA012 reduced the oxacillin MIC 16-fold (Figure 5A).
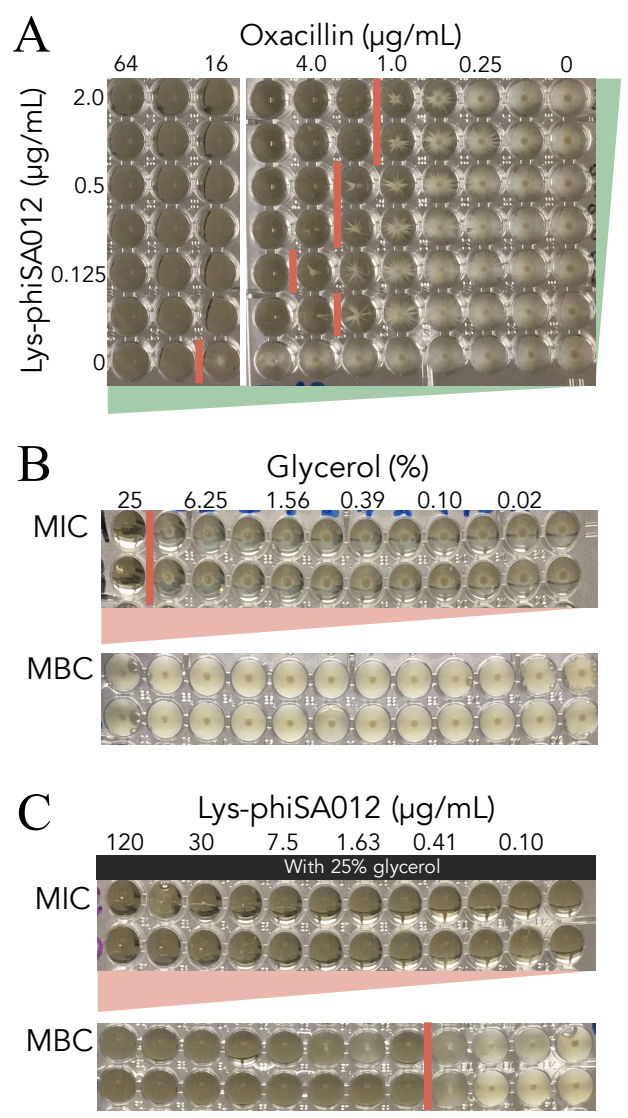

Figure 5. MIC and MBC assays. MIC and MBC assays were performed in 96-well plates. Red lines indicate the border of bacterial growth. (A) MIC assay of oxacillin towards SA003 with or without Lys-phiSA012. (B) MIC and MBC assays of glycerol towards SA003. (C) MIC and MBC assays of Lys-phiSA012 with 25\% glycerol towards SA003. 
Next, we examined suitable vehicles for endolysins. As shown in Figure 5B, 25\% glycerol inhibited SA003 growth in MIC assays due to its bacteriostatic (and not bactericidal) activity, given that bacterial growth resumed after subculture, as confirmed by MBC assays (Figure 5B). An accurate MIC for Lys-phiSA012 could not be determined due to the initial high lytic activity of endolysins, as shown in Figure 2A-D and 3C, and their subsequent inactivation during overnight incubation. However, Lys-phiSA012 in 25\% glycerol inhibited bacterial growth as shown by MIC assay after overnight incubation. Furthermore, the MBC of Lys-phiSA012 in $25 \%$ glycerol decreased at $\geq 0.815 \mu \mathrm{g} / \mathrm{mL}$ (Figure 5C).

\section{Discussion}

The discovery of penicillin by Alexander Fleming in 1928 lead to the purification and development of antibiotics in the 1940s, called the beginning of the era of antibiotics. The prevailing feeling during this era was that bacterial infectious diseases would be overcome by the development of various antibiotics. However, these antibiotics are no longer as effective as they were 70 years ago [5]. Furthermore, Gram-negative pathogens resistant to colistin, the last resort antibiotic against MDR, have been reported [64,65]. On the other hand, a personalized bacteriophage-based treatment approved by the Food and Drug Administration (FDA) of the United States as an emergency investigational new drug (eIND) was administered to a 68-year-old patient infected with multidrug-resistant Acinetobacter baumannii and resulted in dramatic improvement from a comatose state, despite the patient not responding to several antibiotics, including colistin [66]. In addition, the efficient lytic capability of endolysins towards MRSA in an in vivo assay has been reported $[43,67,68]$. These data suggested that the therapeutic use of bacteriophages could be applicable to similar cases, and endolysins might have the same potential as bacteriophages.

The present study has clearly demonstrated that Lys-phiSA012 shows high lytic activity towards $S$. aureus, including MRSA strains. The $\mathrm{OD}_{600}$ was reduced within a few minutes of adding Lys-phiSA012, and bacterial growth was clearly inhibited in the turbidity reduction assay, as it was previously shown for Lys-phiK [69]. Lys-phiSA012 also showed lytic activity towards S. pseudintermidius and S. haemoliticus (Figure 2A-C) but not towards Streptococcus agalactiae (Figure 2D), indicating that it has a specific antimicrobial spectrum limited to staphylococci, including MDR S. aureus. Specific host ranges of bacteriophages and endolysins could be advantageous for clinical applications as they would not disrupt our normal microbiota. Broad host ranges of bacteriophage SA012 [28], bacteriophage K [70] and bacteriophage Twort [71] towards S. aureus strains have been reported but the amino acid sequences of their endolysins showed incomplete identity. In particular, the sequence similarity between Lys-phiSA012 and Lys-phiTwort is less than 50\% (Figure 1C), suggesting that endolysins have evolved to have highly diverse activities, allowing us to select the most effective and specific endolysin for combatting a specific bacterial strain. Further evaluation of Lys-phiSA012 efficacy in vivo is needed prior to its clinical application. In addition, Lys-phiSA012 showed high lytic activity within a few minutes, as shown in Figure 2A-C, which might lead to the rapid release of toxins from lysed bacterial cells. Therefore, it may be necessary to develop extended release Lys-phiSA012 that kill bacteria gradually in the body.

The recognition of peptidoglycans by endolysins determines their spectrum of activity and is regulated by a SH3b domain which binds a highly specific bacterial ligand [72]. In addition, the maximum lytic activities of several endolysins, such as Lys-phiK [45], LytA [73], and lysostaphin [74], depend on a SH3b domain. As shown in Figure 3C, Lys-phiSA012WT and $\Delta \mathrm{mt2}$, both containing CHAP-SH3b, showed maximum lytic activity towards SA003, suggesting that the Lys-phiSA012 SH3b domain is required for catalytic activity of the CHAP domain and plays a critical role in cell lysis. In addition, $\Delta \mathrm{mt} 3$, which contains AMID-SH3b, showed no lytic activity, indicating that the AMID domain of Lys-phiSA012 may not play an essential role in lytic activity towards SA003 as assessed using turbidity reduction assays, or that deletion of this domain might cause conformational 
changes leading to defective lytic activity. These data are consistent with previous reports regarding various staphylococcal endolysins harboring a SH3b domain [73,75].

A Ca ${ }^{2+}$-binding site in the CHAP domain and a $\mathrm{Zn}^{2+}$-binding site in the AMID domain of Lys-phiSA012 were identified by bioinformatics analysis (Figure 4A,B). We estimated that the presence of $\mathrm{Zn}^{2+}$ might not effect lytic activity significantly because $\Delta \mathrm{mt} 3$ might not efficiently lyse bacterial cell wall peptidoglycan; however, high lytic activity was observed in the presence of $100 \mu \mathrm{M} \mathrm{Zn^{2+ }}$ (Figure 4C). It was reported that the CHAP domain of Lys-phiK, which has $99.39 \%$ amino acid sequence identity (Table 3, Figure A1A) with that of Lys-phiSA012, also harbors a $\mathrm{Zn}^{2+}$-binding site [64] based on structural analysis. We suggest that $\mathrm{Zn}^{2+}$ affects not only the AMID domain but also the CHAP domain, leading to potent lytic activity. Furthermore, Donovan et al. [73] and Becker et al. [50] provided clues for the relationship between the catalytic roles of the CHAP and AMID domains, suggesting that endolysins harboring dual lytic domains derived from staphylococcal phages might respond differently (i.e., either exolytic or endolytic) to bacterial peptidoglycan. Here, we demonstrated that divalent ions in the medium play a critical role in the lytic activity of Lys-phiSA012 (Figure A2), and maximum lytic activity was observed in the presence of at least $1 \mathrm{mM} \mathrm{Ca}^{2+}$, consistent with the extracellular concentration of $\mathrm{Ca}^{2+}$ which is closely regulated at around $1.2 \mathrm{mM}[76]$, and $100 \mu \mathrm{M} \mathrm{Zn}^{2+}$, consistent with the intracellular concentration of $\mathrm{Zn}^{2+}$ [77]. Taken together, we suggest that Lys-phiSA012 is activated by divalent ions, especially $\mathrm{Ca}^{2+}$ and $\mathrm{Zn}^{2+}$, at specific minimum concentrations, binding to a specific site in the catalytic domains. As we known, the present study is the first to characterize the optimal range of $\mathrm{Ca}^{2+}$ and $\mathrm{Zn}^{2+}$ concentrations for the lytic activity of Lys-phiK and LysK-like endolysins. Changes in the amino acid residues in the CHAP and AMID domain among Lys-phiK, Lys-phiSA012 and other LysK-like endolysins (Table 4) are not located at the $\mathrm{Ca}^{2+}-\mathrm{Zn}^{2+}$-binding sites (Figure 4C), suggesting that at least $1 \mathrm{mM} \mathrm{Ca}^{2+}$ and $100 \mu \mathrm{M} \mathrm{Zn}^{2+}$ might be required for efficient Lys-phiK and LysK-like endolysin lytic activity. Further investigations are needed to clarify the relationship between amino acid change(s) and the lytic activity of LysK-like endolysins compared to the lytic activity of Lys-phiK. In particular, further studies of the role of Ser83Asn found in more than half of LysK-like endolysins, including Lys-phiSA012 (Table 4, Figure 3C), are required because it was previously reported that certain single amino acid changes in the CHAP domain of Lys-phiK enhance lytic activity toward S. aureus stains [78].

It was reported that the CHAP domain of Lys-phiK cleaves at the pentaglycine linkage between peptidoglycan chains and that the AMID domain of Lys-phiK cleaves between $\mathrm{N}$-acetylmuramic acid and L-alanine [45,79]. The mechanism underlying cell wall peptidoglycan digestion is different between endolysins and other antibiotics, and thus we tested the efficacy of Lys-phiSA012 with oxacillin towards S. aureus. As shown in Figure 5A, endolysins have significant potential for reducing antibiotics use because Lys-phiSA012 decreased the MIC of oxacillin more than 16-fold. In addition, the bactericidal activity of Lys-phiSA012 was shown to be limited in the presence of $25 \%$ glycerol, which we used as a vehicle for Lys-phiSA012 (Figure 5C). Notably, it was previously reported that MIC of Lys-phiK towards S. aureus is $78 \pm 20 \mu \mathrm{g} / \mathrm{mL}$ [45]. A large amount of Lys-phiK might be required to kill these bacteria completely due to the inactivation of endolysin during overnight incubation in MIC assays; however, Lys-phiSA012 ( $\geq 0.815 \mu \mathrm{g} / \mathrm{mL})$ with $25 \%$ glycerol clearly inhibited bacterial growth in the present study, suggesting that the combination of Lys-phiSA012 with bacteriostatic agents might enhance and prolong the lytic activity of endolysins.

Generally, endolysins can directly access and subsequently digest the cell wall peptidoglycans of Gram-positive bacteria, as shown in Figure 2A, but are largely ineffective towards Gram-negative bacteria due to the outer membrane barrier [25,34]. In addition, some bacteria, including S. aureus, can move into the intracellular spaces to escape the immune system, making antibiotics and endolysins ineffective because they cannot access the cytosol due to the cellular membrane [80]. However, endolysins can be engineered to overcome their limited activity towards Gram-negative and intracellular bacteria by being fused to outer membrane permeabilizing peptides, allowing their 
transfer across the membrane barrier [81-83]. Further investigations are needed to develop Lys-phiSA012 for use against intracellular S. aureus.

In conclusion, we purified a LysK-like endolysin, Lys-phiSA012, and demonstrated that its highly potent lytic activity towards staphylococci is not limited to $S$. aureus. Furthermore, our results suggest optimal conditions for Lys-phiK and LysK-like endolysins. Our results will contribute to the understanding of LysK-like endolysins and to promoting the development of alternatives for antibiotics, leading to the reduction of antibiotic-resistant bacteria and supporting the proper use of antibiotics.

Supplementary Materials: The following are available online at www.mdpi.com/1424-8247/11/1/25/s1.

Acknowledgments: This study was supported in part by the Japan Society for the Promotion of Science (JSPS) KAKENHI, Grant-in-Aid for Scientific Research (B) program (numbers 22380174, 25292182) and (A) program (number 17H01506), and the Ministry of Education, Culture, Sports, Science and Technology of Japan (MEXT)-Supported Program for the Strategic Research Foundation at Private Universities, 2013-2017.

Author Contributions: Hidetoshi Higuchi, Yasunori Tanji, Yutaka Tamura and Hidetomo Iwano conceived and designed the experiments; Masaru Usui contributed reagents, materials and analysis tools; Jumpei Fujiki, Tomohiro Nakamura, Takaaki Furusawa, Hazuki Ohno, Hiromichi Takahashi and Junya Kitana performed experiments and analyzed the data; and Jumpei Fujiki and Hidetomo Iwano wrote the paper.

Conflicts of Interest: The authors declare no conflict of interest.

\section{Appendix A}

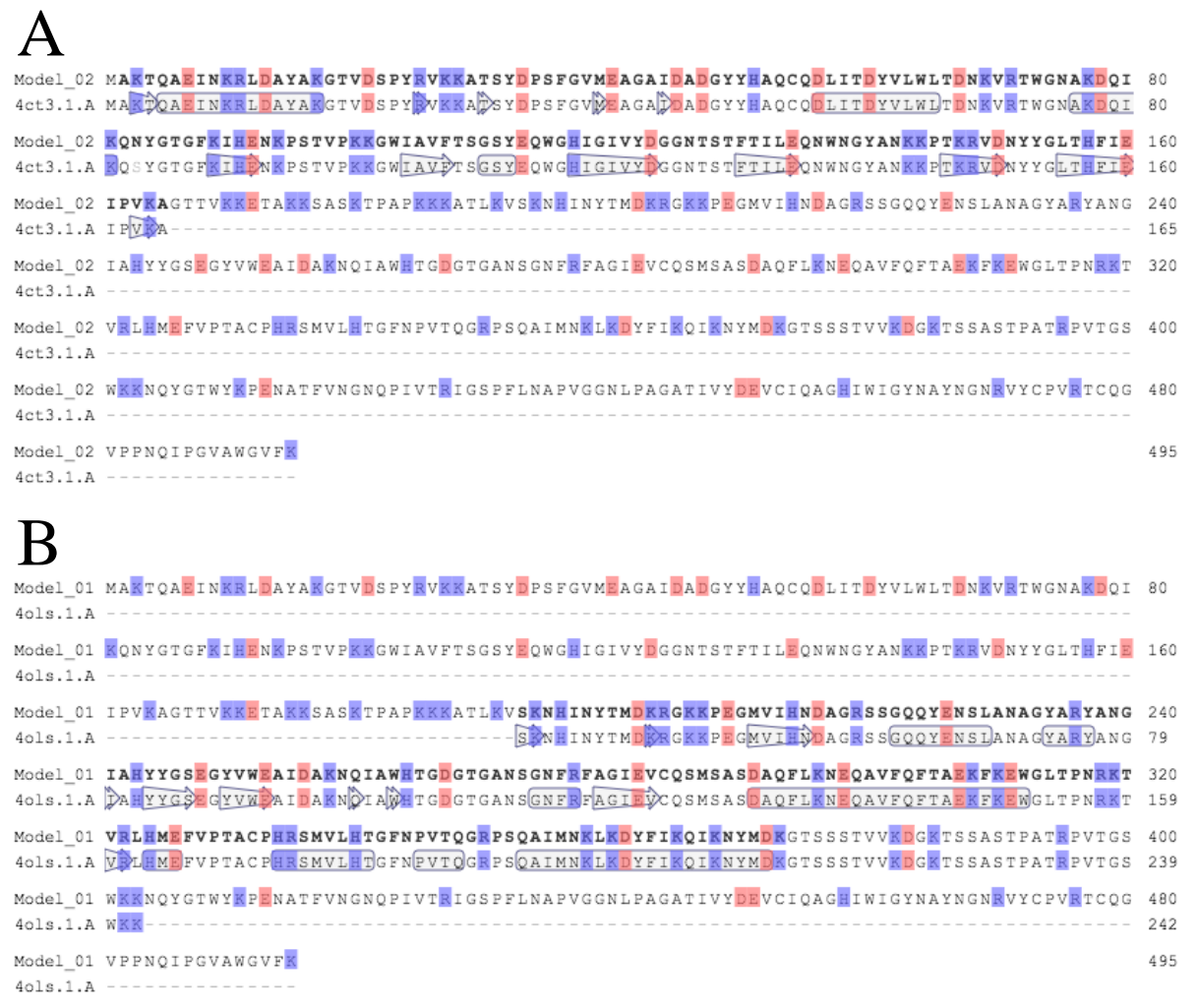

Figure A1. Model-template alignment in the protein structure model. Circles and arrows represent alpha-helices and beta-strands, respectively. Blue: positively charged amino acids, red: negatively charged amino acids. (A) Model-template alignment of the CHAP domain. Model_02; Lys-phiSA012 sequence. 4act. 1. A; Lys-phiK sequence. Lys-phiSA012 and Lys-phiK alignments of the other domains are described in Figure 1. (B) Model-template alignment of the AMID domain. Model_01; Lys-phiSA012 sequence. 4ols. 1. A; Lys-phiGH15 sequence. Lys-phiSA012 and Lys-phiGH15 alignments of the other domains are described in Figure 1. These data were analyzed using the SWISS-MODEL server. 


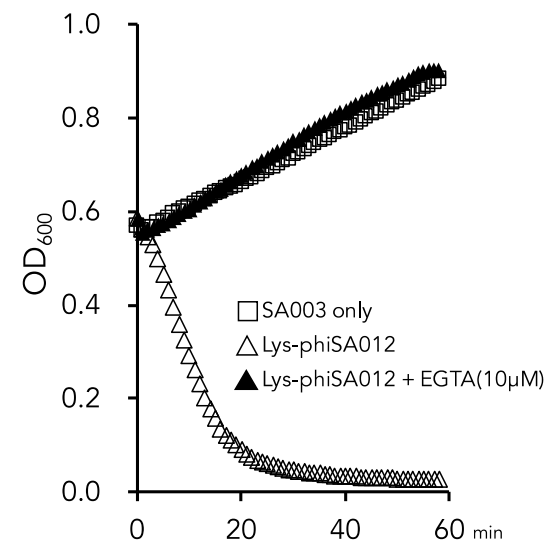

Figure A2. The effect of EGTA treatment on Lys-phiSA012 lytic activity. The lytic activity of Lys-phiSA012 w/wo EGTA was determined using the turbidity reduction assay. SA003 was grown in LB medium w/wo $10 \mathrm{mM}$ EGTA and the assays were initiated by the addition of $64 \mu \mathrm{g} / \mathrm{mL}$ Lys-phiSA012.

\section{References}

1. Maragakis, L.L.; Perencevich, E.N.; Cosgrove, S.E. Clinical and economic burden of antimicrobial resistance. Expert Rev. Anti-Infect. Ther. 2008, 6, 751-763. [CrossRef] [PubMed]

2. De Kraker, M.E.; Wolkewitz, M.; Davey, P.G.; Koller, W.; Berger, J.; Nagler, J.; Icket, C.; Kalenic, S.; Horvatic, J.; Seifert, H.; et al. Clinical impact of antimicrobial resistance in European hospitals: Excess mortality and length of hospital stay related to methicillin-resistant Staphylococcus aureus bloodstream infections. Antimicrob. Agents Chemother. 2011, 55, 1598-1605. [CrossRef] [PubMed]

3. De Kraker, M.E.; Davey, P.G.; Grundmann, H.; Burden Study Group. Mortality and hospital stay associated with resistant Staphylococcus aureus and Escherichia coli bacteremia: Estimating the burden of antibiotic resistance in europe. PLoS Med. 2011, 8, e1001104. [CrossRef] [PubMed]

4. Asai, T.; Kojima, A.; Harada, K.; Ishihara, K.; Takahashi, T.; Tamura, Y. Correlation between the usage volume of veterinary therapeutic antimicrobials and resistance in Escherichia coli isolated from the feces of food-producing animals in japan. Jpn. J. Infect. Dis. 2005, 58, 369-372. [PubMed]

5. Golkar, Z.; Bagasra, O.; Pace, D.G. Bacteriophage therapy: A potential solution for the antibiotic resistance crisis. J. Infect. Dev. Ctries. 2014, 8, 129-136. [CrossRef] [PubMed]

6. Silbergeld, E.K.; Graham, J.; Price, L.B. Industrial food animal production, antimicrobial resistance, and human health. Annu. Rev. Public Health 2008, 29, 151-169. [CrossRef] [PubMed]

7. Sarmah, A.K.; Meyer, M.T.; Boxall, A.B. A global perspective on the use, sales, exposure pathways, occurrence, fate and effects of veterinary antibiotics (VAs) in the environment. Chemosphere 2006, 65, 725-759. [CrossRef] [PubMed]

8. Li, Y.X.; Zhang, X.L.; Li, W.; Lu, X.F.; Liu, B.; Wang, J. The residues and environmental risks of multiple veterinary antibiotics in animal faeces. Environ. Monit. Assess 2013, 185, 2211-2220. [CrossRef] [PubMed]

9. Smith, T.C.; Gebreyes, W.A.; Abley, M.J.; Harper, A.L.; Forshey, B.M.; Male, M.J.; Martin, H.W.; Molla, B.Z.; Sreevatsan, S.; Thakur, S.; et al. Methicillin-resistant Staphylococcus aureus in pigs and farm workers on conventional and antibiotic-free swine farms in the USA. PLoS ONE 2013, 8, e63704. [CrossRef] [PubMed]

10. Neyra, R.C.; Frisancho, J.A.; Rinsky, J.L.; Resnick, C.; Carroll, K.C.; Rule, A.M.; Ross, T.; You, Y.; Price, L.B.; Silbergeld, E.K. Multidrug-resistant and methicillin-resistant Staphylococcus aureus (MRSA) in hog slaughter and processing plant workers and their community in North Carolina (USA). Environ. Health Perspect. 2014, 122, 471-477. [PubMed]

11. Khanna, T.; Friendship, R.; Dewey, C.; Weese, J.S. Methicillin resistant Staphylococcus aureus colonization in pigs and pig farmers. Vet. Microbiol. 2008, 128, 298-303. [CrossRef] [PubMed]

12. Smith, T.C. Livestock-associated Staphylococcus aureus: The United States experience. PLoS Pathog. 2015, 11, e1004564. [CrossRef] [PubMed] 
13. Geenen, P.L.; Graat, E.A.; Haenen, A.; Hengeveld, P.D.; Van Hoek, A.H.; Huijsdens, X.W.; Kappert, C.C.; Lammers, G.A.; Van Duijkeren, E.; Van De Giessen, A.W. Prevalence of livestock-associated MRSA on Dutch broiler farms and in people living and/or working on these farms. Epidemiol. Infect. 2013, 141, 1099-1108. [CrossRef] [PubMed]

14. Morcillo, A.; Castro, B.; Rodriguez-Alvarez, C.; Gonzalez, J.C.; Sierra, A.; Montesinos, M.I.; Abreu, R.; Arias, A. Prevalence and characteristics of methicillin-resistant Staphylococcus aureus in pigs and pig workers in Tenerife, Spain. Foodborne Pathog. Dis. 2012, 9, 207-210. [CrossRef] [PubMed]

15. Denis, O.; Suetens, C.; Hallin, M.; Catry, B.; Ramboer, I.; Dispas, M.; Willems, G.; Gordts, B.; Butaye, P.; Struelens, M.J. Methicillin-resistant Staphylococcus aureus st398 in swine farm personnel, Belgium. Emerg. Infect. Dis. 2009, 15, 1098-1101. [CrossRef] [PubMed]

16. Aubry-Damon, H.; Grenet, K.; Sall-Ndiaye, P.; Che, D.; Cordeiro, E.; Bougnoux, M.E.; Rigaud, E.; Le Strat, Y.; Lemanissier, V.; Armand-Lefevre, L.; et al. Antimicrobial resistance in commensal flora of pig farmers. Emerg. Infect. Dis. 2004, 10, 873-879. [CrossRef] [PubMed]

17. Sordillo, L.M.; Streicher, K.L. Mammary gland immunity and mastitis susceptibility. J. Mammary Gland Biol. Neoplasia 2002, 7, 135-146. [CrossRef] [PubMed]

18. Yamane, I. Epidemiological survey and economical evaluation of bovine mastitis in tie-stall dairy farms. J. Jpn. Vet. Med. Assoc. 2006, 59, 674-678. [CrossRef]

19. Costa, E.O.; Benites, N.R.; Guerra, J.L.; Melville, P.A. Antimicrobial susceptibility of Staphylococcus spp. isolated from mammary parenchymas of slaughtered dairy cows. J. Vet. Med. B Infect. Dis. Vet. Public Health 2000, 47, 99-103. [CrossRef] [PubMed]

20. Aires-de-Sousa, M. Methicillin-resistant Staphylococcus aureus among animals: Current overview. Clin. Microbiol. Infect. 2017, 23, 373-380. [CrossRef] [PubMed]

21. De Kraker, M.E.; Stewardson, A.J.; Harbarth, S. Will 10 million people die a year due to antimicrobial resistance by 2050? PLoS Med. 2016, 13, e1002184. [CrossRef] [PubMed]

22. O'Neill, L.J. Review on Antimicrobial Resistance Antimicrobial Resistance: Tackling a Crisis for the Health and Wealth of Nations. Available online: https:/ / amr-review.org/sites/default/files/AMR\%20Review\% 20Paper\%20-\%20Tackling\%20a\%20crisis\%20for\%20the\%20health\%20and\%20wealth\%20of\%20nations_1. pdf (accessed on 22 February 2018).

23. Haddad Kashani, H.; Schmelcher, M.; Sabzalipoor, H.; Seyed Hosseini, E.; Moniri, R. Recombinant endolysins as potential therapeutics against antibiotic-resistant Staphylococcus aureus: Current status of research and novel delivery strategies. Clin. Microbiol. Rev. 2018, 31. [CrossRef]

24. Cisek, A.A.; Dabrowska, I.; Gregorczyk, K.P.; Wyzewski, Z. Phage therapy in bacterial infections treatment: One hundred years after the discovery of bacteriophages. Curr. Microbiol. 2017, 74, 277-283. [CrossRef] [PubMed]

25. Doss, J.; Culbertson, K.; Hahn, D.; Camacho, J.; Barekzi, N. A review of phage therapy against bacterial pathogens of aquatic and terrestrial organisms. Viruses 2017, 9, 50. [CrossRef] [PubMed]

26. Furusawa, T.; Iwano, H.; Hiyashimizu, Y.; Matsubara, K.; Higuchi, H.; Nagahata, H.; Niwa, H.; Katayama, Y.; Kinoshita, Y.; Hagiwara, K.; et al. Phage therapy is effective in a mouse model of bacterial equine keratitis. Appl. Environ. Microbiol. 2016, 82, 5332-5339. [CrossRef] [PubMed]

27. Furusawa, T.; Iwano, H.; Higuchi, H.; Yokota, H.; Usui, M.; Iwasaki, T.; Tamura, Y. Bacteriophage can lyse antibiotic-resistant Pseudomonas aeruginosa isolated from canine diseases. J. Vet. Med. Sci. 2016, 78, 1035-1038. [CrossRef] [PubMed]

28. Synnott, A.J.; Kuang, Y.; Kurimoto, M.; Yamamichi, K.; Iwano, H.; Tanji, Y. Isolation from sewage influent and characterization of novel Staphylococcus aureus bacteriophages with wide host ranges and potent lytic capabilities. Appl. Environ. Microbiol. 2009, 75, 4483-4490. [CrossRef] [PubMed]

29. Iwano, H.; Inoue, Y.; Takasago, T.; Kobayashi, H.; Furusawa, T.; Taniguchi, K.; Fujiki, J.; Yokota, H.; Usui, M.; Tanji, Y.; et al. Bacteriophage $\Phi S A 012$ has a broad host range against Staphylococcus aureus and effective lytic capacity in a mouse mastitis model. Biology 2018, 8, 7.

30. Meaden, S.; Koskella, B. Exploring the risks of phage application in the environment. Front. Microbiol. 2013, 4, 358. [CrossRef] [PubMed]

31. Nobrega, F.L.; Costa, A.R.; Kluskens, L.D.; Azeredo, J. Revisiting phage therapy: New applications for old resources. Trends Microbiol. 2015, 23, 185-191. [CrossRef] [PubMed] 
32. Guo, M.; Feng, C.; Ren, J.; Zhuang, X.; Zhang, Y.; Zhu, Y.; Dong, K.; He, P.; Guo, X.; Qin, J. A novel antimicrobial endolysin, lyspa26, against Pseudomonas aeruginosa. Front. Microbiol. 2017, 8, 293. [CrossRef] [PubMed]

33. Loeffler, J.M.; Nelson, D.; Fischetti, V.A. Rapid killing of Streptococcus pneumoniae with a bacteriophage cell wall hydrolase. Science 2001, 294, 2170-2172. [CrossRef] [PubMed]

34. Fischetti, V.A. Bacteriophage lytic enzymes: Novel anti-infectives. Trends Microbiol. 2005, 13, 491-496. [CrossRef] [PubMed]

35. Schuch, R.; Nelson, D.; Fischetti, V.A. A bacteriolytic agent that detects and kills bacillus anthracis. Nature 2002, 418, 884-889. [CrossRef] [PubMed]

36. Pastagia, M.; Euler, C.; Chahales, P.; Fuentes-Duculan, J.; Krueger, J.G.; Fischetti, V.A. A novel chimeric lysin shows superiority to mupirocin for skin decolonization of methicillin-resistant and -sensitive Staphylococcus aureus strains. Antimicrob. Agents Chemother. 2011, 55, 738-744. [CrossRef] [PubMed]

37. Rodriguez-Rubio, L.; Martinez, B.; Rodriguez, A.; Donovan, D.M.; Gotz, F.; Garcia, P. The phage lytic proteins from the Staphylococcus aureus bacteriophage vB_SauS-phiiPLA88 display multiple active catalytic domains and do not trigger staphylococcal resistance. PLoS ONE 2013, 8, e64671. [CrossRef] [PubMed]

38. Domenech, M.; Garcia, E.; Moscoso, M. In vitro destruction of Streptococcus pneumoniae biofilms with bacterial and phage peptidoglycan hydrolases. Antimicrob. Agents Chemother. 2011, 55, 4144-4148. [CrossRef] [PubMed]

39. Schuch, R.; Khan, B.K.; Raz, A.; Rotolo, J.A.; Wittekind, M. Bacteriophage lysin cf-301, a potent antistaphylococcal biofilm agent. Antimicrob. Agents Chemother. 2017, 61. [CrossRef] [PubMed]

40. O'Flaherty, S.; Coffey, A.; Meaney, W.; Fitzgerald, G.F.; Ross, R.P. The recombinant phage lysin lysk has a broad spectrum of lytic activity against clinically relevant staphylococci, including methicillin-resistant Staphylococcus aureus. J. Bacteriol. 2005, 187, 7161-7164. [CrossRef] [PubMed]

41. Gu, J.; Xu, W.; Lei, L.; Huang, J.; Feng, X.; Sun, C.; Du, C.; Zuo, J.; Li, Y.; Du, T.; et al. Lysgh15, a novel bacteriophage lysin, protects a murine bacteremia model efficiently against lethal methicillin-resistant Staphylococcus aureus infection. J. Clin. Microbiol. 2011, 49, 111-117. [CrossRef] [PubMed]

42. Loessner, M.J.; Gaeng, S.; Wendlinger, G.; Maier, S.K.; Scherer, S. The two-component lysis system of Staphylococcus aureus bacteriophage twort: A large TTG-start holin and an associated amidase endolysin. FEMS Microbiol. Lett. 1998, 162, 265-274. [CrossRef] [PubMed]

43. Zhang, L.; Li, D.; Li, X.; Hu, L.; Cheng, M.; Xia, F.; Gong, P.; Wang, B.; Ge, J.; Zhang, H.; et al. Lysgh15 kills Staphylococcus aureus without being affected by the humoral immune response or inducing inflammation. Sci. Rep. 2016, 6, 29344. [CrossRef] [PubMed]

44. Gu, J.; Feng, Y.; Feng, X.; Sun, C.; Lei, L.; Ding, W.; Niu, F.; Jiao, L.; Yang, M.; Li, Y.; et al. Structural and biochemical characterization reveals LysGH15 as an unprecedented "EF-Hand-Like" calcium-binding phage lysin. PLoS Pathog. 2014, 10, e1004109. [CrossRef] [PubMed]

45. Becker, S.C.; Dong, S.; Baker, J.R.; Foster-Frey, J.; Pritchard, D.G.; Donovan, D.M. Lysk chap endopeptidase domain is required for lysis of live staphylococcal cells. FEMS Microbiol. Lett. 2009, 294, 52-60. [CrossRef] [PubMed]

46. Sanz-Gaitero, M.; Keary, R.; Garcia-Doval, C.; Coffey, A.; van Raaij, M.J. Crystal structure of the lytic chap(k) domain of the endolysin Lysk from Staphylococcus aureus bacteriophage k. Virol. J. 2014, 11, 133. [CrossRef] [PubMed]

47. Ishihara, K.; Shimokubo, N.; Sakagami, A.; Ueno, H.; Muramatsu, Y.; Kadosawa, T.; Yanagisawa, C.; Hanaki, H.; Nakajima, C.; Suzuki, Y.; et al. Occurrence and molecular characteristics of methicillin-resistant Staphylococcus aureus and methicillin-resistant Staphylococcus pseudintermedius in an academic veterinary hospital. Appl. Environ. Microbiol. 2010, 76, 5165-5174. [CrossRef] [PubMed]

48. Ishihara, K.; Saito, M.; Shimokubo, N.; Muramatsu, Y.; Maetani, S.; Tamura, Y. Methicillin-resistant Staphylococcus aureus carriage among veterinary staff and dogs in private veterinary clinics in Hokkaido, Japan. Microbiol. Immunol. 2014, 58, 149-154. [CrossRef] [PubMed]

49. clinical and Laboratory standards Institute. Performance standards for antimicrobial susceptibility testing. Twenty-First Inf. Suppl. 2011, 31, 68-76.

50. Becker, S.C.; Swift, S.; Korobova, O.; Schischkova, N.; Kopylov, P.; Donovan, D.M.; Abaev, I. Lytic activity of the staphylolytic Twort phage endolysin CHAP domain is enhanced by the SH3b cell wall binding domain. FEMS Microbiol. Lett. 2015, 362, 1-8. [CrossRef] [PubMed] 
51. Son, B.; Yun, J.; Lim, J.A.; Shin, H.; Heu, S.; Ryu, S. Characterization of lysb4, an endolysin from the Bacillus cereus-infecting bacteriophage b4. BMC Microbiol. 2012, 12, 33. [CrossRef] [PubMed]

52. Sader, H.S.; Flamm, R.K.; Jones, R.N. Antimicrobial activity of daptomycin tested against Gram-positive pathogens collected in Europe, Latin America, and selected countries in the Asia-Pacific region (2011). Diagn. Microbiol. Infect. Dis. 2013, 75, 417-422. [CrossRef] [PubMed]

53. Arnold, K.; Bordoli, L.; Kopp, J.; Schwede, T. The swiss-model workspace: A web-based environment for protein structure homology modelling. Bioinformatics 2006, 22, 195-201. [CrossRef] [PubMed]

54. Kiefer, F.; Arnold, K.; Kunzli, M.; Bordoli, L.; Schwede, T. The swiss-model repository and associated resources. Nucleic Acids Res. 2009, 37, D387-D392. [CrossRef] [PubMed]

55. Guex, N.; Peitsch, M.C.; Schwede, T. Automated comparative protein structure modeling with SWISS-MODEL and SWISS-PDBVIEWER: A historical perspective. Electrophoresis 2009, 30, S162-S173. [CrossRef] [PubMed]

56. Biasini, M.; Bienert, S.; Waterhouse, A.; Arnold, K.; Studer, G.; Schmidt, T.; Kiefer, F.; Gallo Cassarino, T.; Bertoni, M.; Bordoli, L.; et al. Swiss-Model: Modelling protein tertiary and quaternary structure using evolutionary information. Nucleic Acids Res. 2014, 42, W252-W258. [CrossRef] [PubMed]

57. Abatangelo, V.; Peressutti Bacci, N.; Boncompain, C.A.; Amadio, A.F.; Carrasco, S.; Suarez, C.A.; Morbidoni, H.R. Broad-range lytic bacteriophages that kill Staphylococcus aureus local field strains. PLoS ONE 2017, 12, e0181671. [CrossRef] [PubMed]

58. Takemura-Uchiyama, I.; Uchiyama, J.; Kato, S.; Inoue, T.; Ujihara, T.; Ohara, N.; Daibata, M.; Matsuzaki, S. Evaluating efficacy of bacteriophage therapy against Staphylococcus aureus infections using a silkworm larval infection model. FEMS Microbiol. Lett. 2013, 347, 52-60. [CrossRef] [PubMed]

59. Alves, D.R.; Gaudion, A.; Bean, J.E.; Perez Esteban, P.; Arnot, T.C.; Harper, D.R.; Kot, W.; Hansen, L.H.; Enright, M.C.; Jenkins, A.T. Combined use of bacteriophage $\mathrm{k}$ and a novel bacteriophage to reduce Staphylococcus aureus biofilm formation. Appl. Environ. Microbiol. 2014, 80, 6694-6703. [CrossRef] [PubMed]

60. Gutierrez, D.; Vandenheuvel, D.; Martinez, B.; Rodriguez, A.; Lavigne, R.; Garcia, P. Two phages, phiiPLA-RODI and phiiPLA-C1C, lyse mono- and dual-species staphylococcal biofilms. Appl. Environ. Microbiol. 2015, 81, 3336-3348. [CrossRef] [PubMed]

61. Dreher-Lesnick, S.M.; Schreier, J.E.; Stibitz, S. Development of phage lysin Lysa2 for use in improved purity assays for live biotherapeutic products. Viruses 2015, 7, 6675-6688. [CrossRef] [PubMed]

62. Fenton, M.; Cooney, J.C.; Ross, R.P.; Sleator, R.D.; McAuliffe, O.; O’Mahony, J.; Coffey, A. In silico modeling of the staphylococcal bacteriophage-derived peptidase chap(k). Bacteriophage 2011, 1, 198-206. [CrossRef] [PubMed]

63. Filatova, L.Y.; Donovan, D.M.; Becker, S.C.; Lebedev, D.N.; Priyma, A.D.; Koudriachova, H.V.; Kabanov, A.V.; Klyachko, N.L. Physicochemical characterization of the staphylolytic lysk enzyme in complexes with polycationic polymers as a potent antimicrobial. Biochimie 2013, 95, 1689-1696. [CrossRef] [PubMed]

64. Munoz-Price, L.S.; Poirel, L.; Bonomo, R.A.; Schwaber, M.J.; Daikos, G.L.; Cormican, M.; Cornaglia, G.; Garau, J.; Gniadkowski, M.; Hayden, M.K.; et al. Clinical epidemiology of the global expansion of Klebsiella pneumoniae carbapenemases. Lancet Infect. Dis. 2013, 13, 785-796. [CrossRef]

65. Zou, D.; Huang, S.; Lei, H.; Yang, Z.; Su, Y.; He, X.; Zhao, Q.; Wang, Y.; Liu, W.; Huang, L. Sensitive and rapid detection of the plasmid-encoded colistin-resistance gene mcr-1 in enterobacteriaceae isolates by loop-mediated isothermal amplification. Front. Microbiol. 2017, 8, 2356. [CrossRef] [PubMed]

66. Schooley, R.T.; Biswas, B.; Gill, J.J.; Hernandez-Morales, A.; Lancaster, J.; Lessor, L.; Barr, J.J.; Reed, S.L.; Rohwer, F.; Benler, S.; et al. Development and use of personalized bacteriophage-based therapeutic cocktails to treat a patient with a disseminated resistant Acinetobacter baumannii infection. Antimicrob. Agents Chemother. 2017. [CrossRef] [PubMed]

67. Daniel, A.; Euler, C.; Collin, M.; Chahales, P.; Gorelick, K.J.; Fischetti, V.A. Synergism between a novel chimeric lysin and oxacillin protects against infection by methicillin-resistant Staphylococcus aureus. Antimicrob. Agents Chemother. 2010, 54, 1603-1612. [CrossRef] [PubMed]

68. Rashel, M.; Uchiyama, J.; Ujihara, T.; Uehara, Y.; Kuramoto, S.; Sugihara, S.; Yagyu, K.; Muraoka, A.; Sugai, M.; Hiramatsu, K.; et al. Efficient elimination of multidrug-resistant Staphylococcus aureus by cloned lysin derived from bacteriophage $\Phi$ MR11. J. Infect. Dis. 2007, 196, 1237-1247. [CrossRef] [PubMed]

69. Becker, S.C.; Foster-Frey, J.; Donovan, D.M. The phage k lytic enzyme lysk and lysostaphin act synergistically to kill MRSA. FEMS Microbiol. Lett. 2008, 287, 185-191. [CrossRef] [PubMed] 
70. O'Flaherty, S.; Ross, R.P.; Meaney, W.; Fitzgerald, G.F.; Elbreki, M.F.; Coffey, A. Potential of the polyvalent anti-staphylococcus bacteriophage $\mathrm{k}$ for control of antibiotic-resistant staphylococci from hospitals. Appl. Environ. Microbiol. 2005, 71, 1836-1842. [CrossRef] [PubMed]

71. Pantucek, R.; Rosypalova, A.; Doskar, J.; Kailerova, J.; Ruzickova, V.; Borecka, P.; Snopkova, S.; Horvath, R.; Gotz, F.; Rosypal, S. The polyvalent staphylococcal phage phi 812: Its host-range mutants and related phages. Virology 1998, 246, 241-252. [CrossRef] [PubMed]

72. Schmelcher, M.; Shabarova, T.; Eugster, M.R.; Eichenseher, F.; Tchang, V.S.; Banz, M.; Loessner, M.J. Rapid multiplex detection and differentiation of listeria cells by use of fluorescent phage endolysin cell wall binding domains. Appl. Environ. Microbiol. 2010, 76, 5745-5756. [CrossRef] [PubMed]

73. Donovan, D.M.; Lardeo, M.; Foster-Frey, J. Lysis of staphylococcal mastitis pathogens by bacteriophage phi11 endolysin. FEMS Microbiol. Lett. 2006, 265, 133-139. [CrossRef] [PubMed]

74. Baba, T.; Schneewind, O. Target cell specificity of a bacteriocin molecule: A c-terminal signal directs lysostaphin to the cell wall of Staphylococcus aureus. EMBO J. 1996, 15, 4789-4797. [PubMed]

75. Cheng, Q.; Fischetti, V.A. Mutagenesis of a bacteriophage lytic enzyme plygbs significantly increases its antibacterial activity against group b streptococci. Appl. Microbiol. Biotechnol. 2007, 74, 1284-1291. [CrossRef] [PubMed]

76. Bronner, F. Extracellular and intracellular regulation of calcium homeostasis. Sci. World J. 2001, 1, 919-925. [CrossRef] [PubMed]

77. Kambe, T.; Tsuji, T.; Hashimoto, A.; Itsumura, N. The physiological, biochemical, and molecular roles of zinc transporters in zinc homeostasis and metabolism. Physiol. Rev. 2015, 95, 749-784. [CrossRef] [PubMed]

78. Jun, S.Y.; Jung, G.M.; Son, J.S.; Yoon, S.J.; Choi, Y.J.; Kang, S.H. Comparison of the antibacterial properties of phage endolysins sal-1 and lysk. Antimicrob. Agents Chemother. 2011, 55, 1764-1767. [CrossRef] [PubMed]

79. Lu, J.Z.; Fujiwara, T.; Komatsuzawa, H.; Sugai, M.; Sakon, J. Cell wall-targeting domain of glycylglycine endopeptidase distinguishes among peptidoglycan cross-bridges. J. Biol. Chem. 2006, 281, 549-558. [CrossRef] [PubMed]

80. Loffler, B.; Tuchscherr, L.; Niemann, S.; Peters, G. Staphylococcus aureus persistence in non-professional phagocytes. Int. J. Med. Microbiol. 2014, 304, 170-176. [CrossRef] [PubMed]

81. Briers, Y.; Walmagh, M.; Van Puyenbroeck, V.; Cornelissen, A.; Cenens, W.; Aertsen, A.; Oliveira, H.; Azeredo, J.; Verween, G.; Pirnay, J.P.; et al. Engineered endolysin-based “artilysins" to combat multidrugresistant Gram-negative pathogens. Am. Soc. Microbiol. 2014, 5, e01379-14. [CrossRef] [PubMed]

82. Rodriguez-Rubio, L.; Chang, W.L.; Gutierrez, D.; Lavigne, R.; Martinez, B.; Rodriguez, A.; Govers, S.K.; Aertsen, A.; Hirl, C.; Biebl, M.; et al. 'Artilysation' of endolysin lambdasa2lys strongly improves its enzymatic and antibacterial activity against streptococci. Sci. Rep. 2016, 6, 35382. [CrossRef] [PubMed]

83. Becker, S.C.; Roach, D.R.; Chauhan, V.S.; Shen, Y.; Foster-Frey, J.; Powell, A.M.; Bauchan, G.; Lease, R.A.; Mohammadi, H.; Harty, W.J.; et al. Triple-acting lytic enzyme treatment of drug-resistant and intracellular Staphylococcus aureus. Sci. Rep. 2016, 6, 25063. [CrossRef] [PubMed]

(c) 2018 by the authors. Licensee MDPI, Basel, Switzerland. This article is an open access article distributed under the terms and conditions of the Creative Commons Attribution (CC BY) license (http://creativecommons.org/licenses/by/4.0/). 